\title{
ANTIGUAS EVIDENCIAS DE MINERIA Y METALURGIA EN POZUELOS, SANTO DOMINGO Y COYAHUAYMA IPUNA DE JUJUY, ARGENTINA)
}

\section{ANCIENT EVIDENCE OF MINING AND METALLURGY IN POZUELOS, SANTO DOMINGO AND COYAHUAYMA (PUNA DE JUJUY, ARGENTINA)}

\section{CARLOS I. AngIORAMA \& M. FIORENCIA BECERRA*}

\begin{abstract}
En este artículo presentamos los primeros resultados de una serie de trabajos de campo realizados con el objetivo de identificar evidencias de actividades minero-metalúrgicas en tres áreas de la Puna de Jujuy: 1) Fundiciones y Santo Domingo, 2) el sector sur de la cuenca de Pozuelos, y 3) el valle de Coyahuayma y la porción superior del río Rosario. Estos tres sectores alojan importantes yacimientos de minerales metalíferos utilizados por las sociedades prehispánicas del Noroeste argentino, recursos que cobraron también enorme relevancia durante la época colonial. A partir de las evidencias registradas, asignables a momentos prehispánicos y coloniales, se vislumbra el rol que jugaron las prácticas minero-metalúrgicas en la dinámica de las sociedades puneñas en ambas épocas y en los diferentes sectores.
\end{abstract}

Palabras clave: minería, metalurgia, Puna de Jujuy, época prehispánica, época colonial

In this paper we present the initial results of field studies conducted to identify evidence of mining and metallurgical activities in three areas of the Puna of Jujuy: 1) Fundiciones and Santo Domingo, 2) the southern basin of Pozuelos and 3) the Valley of Coyahuayma and the upper Rosario River. These three areas all have deposits of ores that were used by the pre-Hispanic societies of northwestern Argentina and were also of great importance during colonial times. From recorded evidence assigned to preHispanic and colonial times, we can infer the role played by mining and metallurgical practices in the societies of the Puna of Jujuy in both periods and in different sectors.

Key words: mining, metallurgy, Puna of Jujuy, pre-Hispanic times, colonial times

\section{INTRODUCCIÓN}

La Puna de Jujuy constituye parte del extremo sur del altiplano andino. Se trata de una extensa planicie que se ubica a alturas superiores a los $3600 \mathrm{msnm}$, enclavada entre dos enormes cordilleras y dividida por cordones montañosos menores. En general está sometida a rigurosas condiciones climáticas, donde el intenso frío, la gran sequedad y la elevada radiación solar son los factores más notables. Las precipitaciones son escasas y se producen únicamente durante el verano, y la temperatura oscila entre $\operatorname{los}-20{ }^{\circ} \mathrm{C}$ y los $40{ }^{\circ} \mathrm{C}$, conformando una enorme amplitud térmica. Gran parte de la Puna de Jujuy posee una red hidrográfica poco desarrollada y sumamente ramificada, que configura cuencas endorreicas. Estos factores provocan la existencia de suelos semidesérticos y desérticos, con nulo o escaso desarrollo de niveles húmicos. La vegetación predominante es de tipo xerófila, con una gran escasez de árboles.

Los documentos disponibles reflejan que los primeros europeos, los habitantes coloniales, los viajeros del siglo XIX y hasta los visitantes actuales, han considerado al extremo noroccidental de Argentina como un páramo, un desierto hostil e inhabitable. Sin embargo, la Puna de Jujuy no estuvo deshabitada en época prehispánica ni en época colonial. En algunos sectores abundan

\footnotetext{
* Carlos I. Angiorama \& Florencia Becerra, Conicet, IAM-ISES, San Martín 1545 (4000), San Miguel de Tucumán, Argentina, carlosangiorama@gmail. com,florenciabecerra@gmail.com
} 
pasturas que permitieron el desarrollo de sociedades con un fuerte énfasis en la actividad pastoril, y en ciertos lugares, condiciones especialmente favorables posibilitaron un elevado nivel de actividad agrícola. La fauna silvestre constituyó siempre un recurso de enorme importancia para los habitantes del lugar. Pero además, en la puna se encuentran ciertos recursos exclusivos que ejercieron una enorme atracción tales como la sal, ciertas rocas volcánicas requeridas en época prehispánica para la fabricación de artefactos líticos (como la obsidiana y el basalto), y menas de oro, plata, cobre y estaño.

Estos recursos metalíferos tuvieron una gran importancia para los habitantes de la región. El actual Noroeste Argentino albergó una tradición metalúrgica antigua muy relevante en el contexto de los Andes del sur, que se ve reflejada claramente en la variedad, la complejidad y la cantidad de bienes metálicos producidos y usados en la región. Uno de los centros metalúrgicos más activos durante época prehispánica tardía ha sido la Quebrada de Humahuaca. Estudios arqueometalúrgicos recientes nos han permitido postular que parte del metal procesado en ella habría provenido precisamente de la Puna de Jujuy (fundamentalmente estaño y oro). El aprovechamiento de estos recursos, de tanta relevancia económica y política, habría permitido a los habitantes de los sectores de la Puna menos favorables económicamente, integrarse a las redes de tráfico interregional operantes en aquellos tiempos (Angiorama 2003, 2006).

Durante el siglo xv se produjo la anexión de gran parte del Noroeste Argentino al Tawantinsuyu. Según algunos investigadores, justamente la riqueza en minerales metalíferos de la región y la destreza de los metalurgistas locales han sido dos de los principales motivos por los cuales los inkas se interesaron en estos territorios (Raffino 1978, 1981; González, A. 1980; Raffino et al. 1985; Olivera 1991; González, L. 2004). Es más, se ha planteado que parte de la infraestructura inkaica erigida en algunos sectores de la Puna de Jujuy habría estado vinculada a la explotación y el transporte de los minerales metalíferos (Raffino 1978).

En tiempos coloniales, los metales, especialmente el oro y la plata, tomaron un lugar predominante en la escena política. En realidad, fueron uno de los motores de la conquista española de los territorios americanos. El conocimiento de la existencia de yacimientos de oro y plata en la Puna promovió alrededor del año 1600 el asentamiento de españoles para buscar y explotar esos minerales. La historia de esta región se encuentra teñida por disputas jurisdiccionales debido a estas mismas riquezas (Palomeque 2006). La extracción de oro en vetas, pero especialmente de depósitos aluvionales en la zona de Rinconada y Santa Catalina, ejerció una fuerte atracción para la población española e indígena, que se dedicó al cateo de minas, a la construcción de los ingenios o al trabajo en los lavaderos de oro. A fines del siglo xVIII más del $60 \%$ de la población de la actual Provincia de Jujuy estaba concentrada en esta región (Sica \& Ulloa 2007).

La minería de la plata y el oro se desarrolló a partir de emprendimientos empresariales dirigidos por españoles. No obstante, también se constituyó como una fuente de recursos para los mismos indígenas, quienes por medio de ella podían adquirir productos alóctonos y, sobre todo, pagar el tributo obligatorio. Por otra parte, indirectamente, la actividad minera local y la de regiones aledañas permitió la inclusión de los grupos indígenas a las relaciones mercantiles. Los pastores de la Puna se vieron especialmente vinculados a las exportaciones de lana de vicuñas y camélidos (Palomeque 2000), a la extracción y comercialización de la sal, indispensable para los alimentos requeridos por los centros mineros y para el procesamiento del mineral extraído de las minas de plata (Gil Montero 2004), a la provisión de los alimentos para los trabajadores de los centros mineros y, finalmente, al transporte de todos los bienes y productos involucrados en estas actividades. Sin embargo, a pesar de su importancia, conocemos muy poco sobre las características de las explotaciones mineras a pequeña y mediana escala operadas en esta región, como así también del funcionamiento de los complejos mineros y de las redes que posibilitaron dichos emprendimientos.

En el año 2002 iniciamos una investigación a largo plazo con la finalidad de conocer las características que habrían adquirido la explotación y la circulación de minerales metalíferos en el extremo noroccidental del actual territorio argentino durante época preinkaica tardía, inkaica y colonial. En este marco llevamos adelante una serie de trabajos de campo en tres sectores de la Puna de Jujuy prácticamente inexplorados hasta entonces, desde un punto de vista arqueológico: 1) Fundiciones y Santo Domingo, 2) el sector sur de la cuenca de Pozuelos, y 3) el valle de Coyahuayma y la porción superior del río Rosario (fig. 1). Las tres áreas comparten el hecho de alojar importantes yacimientos de oro, plata, cobre y estaño, los cuatro metales utilizados por las sociedades prehispánicas del Noroeste Argentino, y, sobre todo los dos primeros, de enorme relevancia durante época colonial. En este artículo presentamos los primeros resultados de nuestra investigación. 


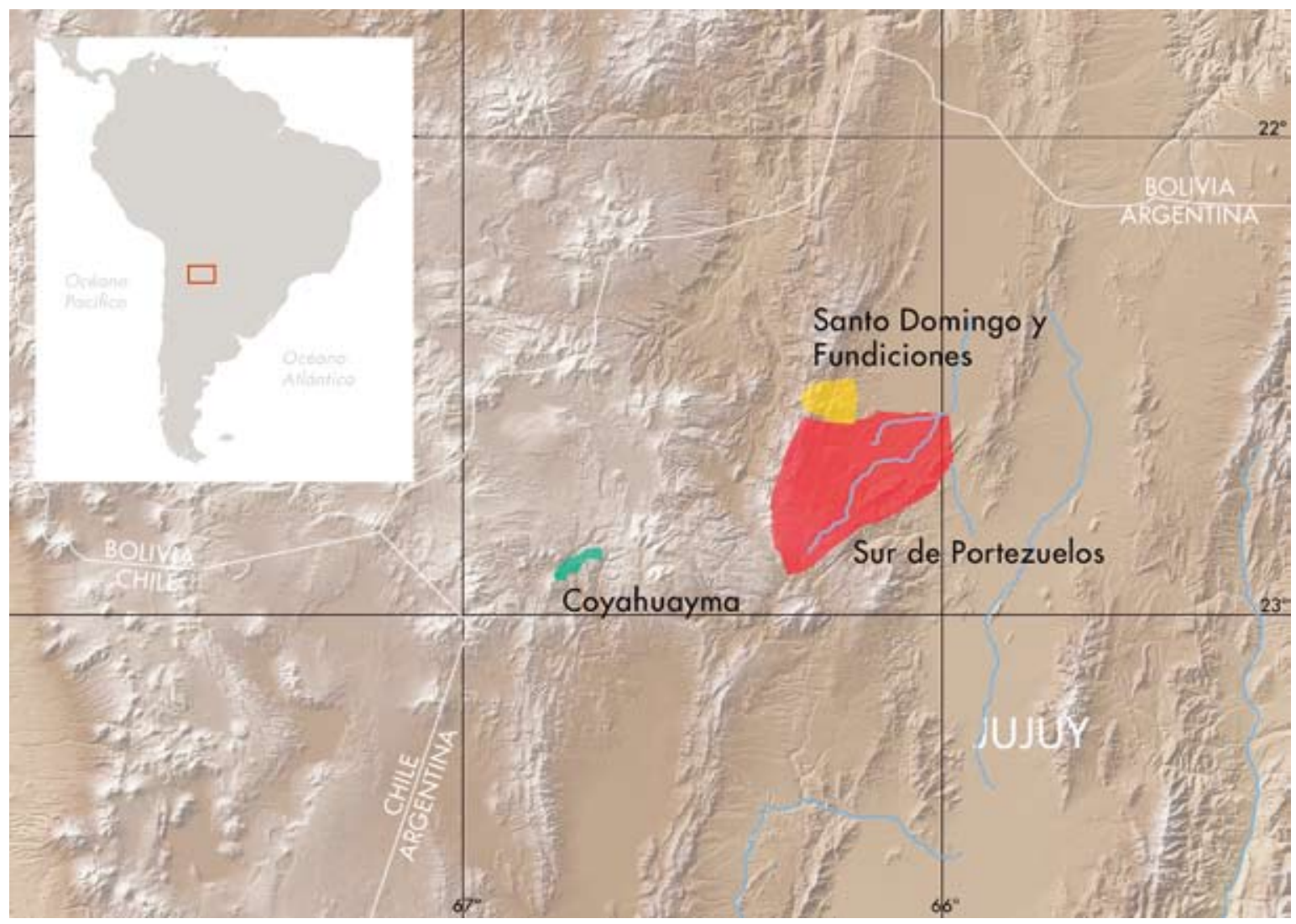

Figura 1. Ubicación de las áreas de estudio.

Figure 1. Location of areas studied.

\section{INFORMACIÓN SOBRE MINERÍA Y METALURGIA ANTIGUA EN LA PUNA DE JUJUY}

\section{Época prehispánica}

La Puna jujeña es una vasta región en la que aún persisten enormes vacíos de información sobre los vestigios prehispánicos que en ella perduran. Esto se debe a que la mayoría de los trabajos arqueológicos de campo se han concentrado en unos pocos sectores, especialmente en los alrededores de las actuales localidades de Yavi, Rinconada, Casabindo y Susques, y, en menor escala, en el curso del río Grande de San Juan y Vilama. Como consecuencia, hoy se cuenta con ciertas "islas" con información sobre momentos prehispánicos rodeadas de enormes áreas desconocidas arqueológicamente.

Lo más estudiado de la Puna jujeña para momentos prehispánicos tardíos son los asentamientos más complejos, en los cuales se han concentrado desde principios del siglo xx la mayoría de los trabajos de campo (Pukará de Rinconada, Casabindo, Doncellas, Pueblo Viejo de Tucute, Yoscaba, Cerro Colorado 1, entre otros). En ellos, sin embargo, se han recuperado escasísimos objetos metálicos y prácticamente no se han registrado evidencias de actividades de producción metalúrgica. En Pueblo Viejo de Tucute o Sorcuyo, emplazado en la ladera oriental de la sierra de Casabindo y ocupado entre el 1000 y el 1400 DC (Albeck 2001), Casanova recuperó únicamente ocho piezas de metal: cinco de cobre (tres cinceles, una campanilla y un fragmento de metal) y tres de oro (dos fragmentos de brazaletes y un adorno semicircular) (Casanova 1938; Pérez 2006-2007).

Las investigaciones llevadas adelante por Alfaro de Lanzone (1988) en Doncellas y Farallones Norte permitieron el hallazgo de algunos objetos de cobre, bronce, plata y hierro. Estos forman parte de la llamada Colección Doncellas, estudiada recientemente por Pérez (2006-2007), y consisten en dos láminas, una campanilla, un tumi, dos colgantes, una "medialuna con pedúnculo", todos de cobre; dos cinceles de bronce, cuatro eslabones de una cadena y una hoja de cuchillo de hierro, todos 
hallados en Doncellas mediante excavación, y dos vasos dorados (con plata como metal predominante), un brazalete y tres colgantes de plata y un topu de bronce, en Farallones. Además de estos objetos, Pérez destaca los hallazgos en el asentamiento de fragmentos de escoria de fundición, posiblemente de cobre, lo que indicaría, según la autora, actividades relacionadas al menos con las primeras etapas del proceso metalúrgico. En otros sitios cuyos hallazgos componen esta colección (Tajuera, Queta y Sayate) también hay trozos de mineral de cobre, una aguja de metal recuperada en el primer sitio y un gancho de hierro en el último.

Otra evidencia probable de la fundición prehispánica tardía de minerales en la región es un fragmento de escoria hallado en un recinto del sitio Cerro Colorado 1, localizado en el sector noreste de la Puna jujeña. Escasos fragmentos cerámicos inkaicos sumados a un fechado radiocarbónico sugieren que la ocupación del sitio perduró durante época Inka (Krapovickas \& Aleksandrowicz 1986-1987; Krapovickas 1987-1988).

La cantidad de objetos metálicos terminados o elementos asociados a su manufactura hallados en la Puna de Jujuy sorprende por su escasez, ya que en asentamientos similares contemporáneos, localizados en la cercana Quebrada de Humahuaca (y en otros sectores del Noroeste Argentino y norte de Chile) es frecuente el hallazgo de piezas de metal y de diversos elementos vinculados con su producción, tales como moldes, crisoles, escoria, residuos metálicos de fundición, etc. (ver por ejemplo, Debenedetti 1910; Schuel 1930; Salas 1945; Ventura 1985; González, A. 1992; Angiorama 2003).

Lamentablemente las áreas en las que se localizan los principales yacimientos metalíferos casi no han sido estudiadas por los arqueólogos. Dos excepciones son el curso del río Grande de San Juan y los alrededores de la localidad de Rinconada, ambos lugares localizados en las cercanías de importantes yacimientos de oro. Sin embargo, los trabajos de campo realizados en el curso del río Grande de San Juan publicados hasta ahora han consistido principalmente en la excavación de tumbas (Lehman-Nistche 1902; Debenedetti 1930; Krapovickas \& Cigliano 1962-1963). En los informes publicados no se menciona ningún elemento que pudiera haber estado vinculado con la explotación del oro de la zona y se ha reportado el hallazgo de solamente un objeto metálico: una placa circular aparentemente de cobre o de alguna aleación de base cobre. En las cercanías de la localidad de Santa Catalina, junto al valle del río Grande de San Juan, existen numerosos pozos y socavones antiguos excavados para la extracción del metal. Sin embargo, aún no se sabe si algunos de ellos fueron realizados en tiempos prehispánicos.
Por otra parte, en la vecindad de la actual localidad de Rinconada se han llevado a cabo trabajos arqueológicos con variada intensidad desde principios del siglo xx. Boman (1992 [1908]) planteó que parte de la enorme cantidad de pozos para extraer sedimento aurífero y lavaderos que rodean al poblado actual habría sido utilizada en época prehispánica. Según Raffino (1978), Puerta de Rinconada, un pequeño asentamiento cercano a una veta aurífera, y el Pukará de Rinconada, un gran pukará tardío remodelado en época Inka, habrían estado relacionados con la explotación de oro en tiempos prehispánicos. No obstante, en ninguno de ellos se han hallado elementos concretos que remitan a actividades minero-metalúrgicas. La única evidencia de una estructura de combustión en el área fue registrada por Rodríguez Orrego (1986), quien describe un horno compuesto, de dos cámaras, localizado en Pan de Azúcar, asociado a cerámica precolombina tardía. Sin embargo, no brinda mayores datos sobre el contexto de hallazgo.

\section{Época colonial}

La minería colonial en la región de estudio es un tema que todavía no ha sido abordado integrando la información geológica, arqueológica e histórica disponible. Desde la etnohistoria se han realizado grandes aportes, haciendo hincapié en la importancia de los recursos mineros del área con relación al poblamiento europeo de la región, a las disputas por las tierras y sus habitantes, y a las actividades productivas y de intercambio (Palomeque 1994, 2006; Gil Montero 2004, 2007; Ulloa 2005; Sica \& Ulloa 2007). Menciones sobre las actividades mineras del área se encuentran además, en escritos, descripciones y mapas confeccionados por viajeros de los siglos XVIII y XIX (Mena 1916 [1772]; Brackebusch 1981 [1883]; Boman 1992 [1908]).

Las investigaciones arqueológicas no se han dedicado específicamente a las evidencias asignables a la época colonial en esta región. Desde la geología, sin embargo, estudiosos de los siglos XIX y principios del xx publicaron información de primer nivel sobre los recursos minerales del área, con algunas referencias a las prácticas mineras pasadas (Hóskold 1889; Sgrosso 1943). La importancia de esta información radica en que muchos de estos datos provienen de observaciones directas en el campo y brindan, por tanto, un panorama de las evidencias materiales que pueden hallarse en cada una de las minas mencionadas. Las síntesis recientes sobre la historia de la minería argentina (como por ejemplo Méndez 1999; Catalano 2004) retoman estas apreciaciones e identifican como centros principales de actividad durante el período colonial a las zonas auríferas y argentíferas de Rinconada, Santo Domingo, 
Santa Catalina, Pan de Azúcar y Coyahuayma en la actual Provincia de Jujuy.

En estos sectores, estos viajeros y geólogos identificaron minas y restos de hornos de fundición abandonados, así como laboreos extensos: galerías, piques, trincheras, escombreras y escorias de fundición (Méndez 1999). En Rosario de Coyahuayma, Sgrosso (1943) reconoce antiguos campamentos mineros, con construcciones aún conservadas y evidencias en terreno de la explotación aurífera intensa. En la zona de Orosmayo este panorama se repite. Las evidencias de las tareas mineras allí realizadas son los materiales removidos, acequias con trampas para retener el mineral, diques y canales (Zappettini 2004). Un escenario similar se da también en Ajedrez, un poblado antiguo destacado por su riqueza en oro, y rodeado por minas abandonadas (Brackebusch 1981 [1883]).

Hóskold (1889) relata que en la Rinconada hay también indicaciones de extensas obras antiguas, tanto en las vetas de oro como en lavaderos de aluvión. La mina de plomo y plata de Pan de Azúcar, en ese departamento, era conocida, según Catalano (2004: 131) "desde el tiempo de los jesuitas", siendo beneficiada por fundición. ${ }^{1}$ En el yacimiento del Paraje de Fundiciones, hoy llamada Mina Chinchillas, los informes de finales del siglo XIX indican también laboreos antiguos (Brackebusch 1981 [1883]; Hóskold 1889; Tello 1988 [1888]).

\section{NUESTROS TRABAJOS}

Como dijimos, las tres áreas trabajadas en búsqueda de evidencias concretas de actividades minero-metalúrgicas fueron los alrededores de Fundiciones y Santo Domingo, con alturas de entre 3.900 y 4.200 msnm; el sector sur de la cuenca de Pozuelos, con alturas de entre 3.600 y $4.200 \mathrm{msnm}$, y el valle de Coyahuayma y la porción superior del río Rosario, con alturas de entre 4.300 y $4.700 \mathrm{msnm}$, todas con enormes riquezas en minerales metalíferos.

Comenzamos los trabajos de campo realizando prospecciones arqueológicas extensivas e intensivas, efectuando relevamientos y muestreos superficiales de cada uno de los sitios hallados, registrando la distribución de los recursos naturales disponibles en los sectores prospectados, y muestreando las fuentes de minerales metalíferos y materias primas líticas presentes (Angiorama 2009a). Las tareas realizadas hasta ahora nos han permitido esbozar un primer panorama de la arqueología del área, registrando más de 300 sitios arqueológicos. Luego, de acuerdo con los objetivos del proyecto, fueron seleccionadas y excavadas o sondeadas una serie de estructuras localizadas en diversos sectores del área. Las prospecciones realizadas nos han permitido registrar diversas evidencias de prácticas minero-metalúrgicas en las tres áreas de interés. Presentamos a continuación una síntesis de los resultados obtenidos hasta el momento.

\section{Hallazgos de época prehispánica}

Las tareas realizadas en Santo Domingo y Fundiciones no nos han permitido hallar hasta el momento indicadores de actividades minero-metalúrgicas que podamos asignar a época prehispánica. En el Sur de Pozuelos, en cambio, en un asentamiento del siglo xIV llamado Tabladitas 1, hemos encontrado restos de un horno de fundición con signos de haber sido sometido a muy altas temperaturas, tales como la alteración observada en las rocas que lo componen y su coloración. El mismo se encuentra casi completamente destruido pero conserva una estructura en forma de "T" de 1,2 x 0,8 m. Junto a él hallamos una gran cantidad de rocas también termoalteradas que pertenecieron originalmente a la estructura, y numerosos fragmentos de minerales y escoria metalúrgica. Si bien no hemos podido datar directamente la estructura de combustión, el hecho de que se localice en un asentamiento del siglo XIV (Angiorama 2009b) que no presenta evidencias coloniales en superficie, y que posea características morfológicas diferentes a las de otros hornos de fundición que hemos datado para época colonial, nos permite asignarle tentativamente una cronología prehispánica.

En una quebrada cercana a la que aloja a Tabladitas 1, llamada Quebrada del río Candado, hemos hallado restos de otro horno de fundición metalúrgica, en este caso asociado a un único recinto de antigüedad desconocida. La estructura de combustión presenta características similares a la de Tabladitas 1, y, al igual que aquella, una morfología diferente a la de los hornos coloniales. Esto nos ha llevado a considerarlo provisoriamente de época prehispánica. Junto a él hemos encontrado algunos fragmentos de escoria metalúrgica. Se observa un muro de unos $4 \mathrm{~m}$ de longitud, construido junto al arroyo temporario para protección del horno.

Es relevante el hecho de que no hayamos encontrado evidencias de actividades vinculadas con minería o metalurgia en ninguno de los contextos que hemos excavado en el sur de Pozuelos. ${ }^{2}$ Esto coincide con los resultados de las extensas excavaciones efectuadas por otros investigadores en el Pukará de Rinconada, el asentamiento más grande y complejo de la región, en el que aparentemente tampoco se han hallado evidencias de ellas.

Finalmente, en Coyahuayma hemos registrado la presencia de algunos socavones y de una enorme cantidad de pozos para la extracción de oro de filones y de sus depósitos aluviales junto a estructuras residenciales 
probablemente vinculadas a estas tareas mineras (fig. 2). Junto a unos socavones de época subactual, además, hemos hallado un área de unos $10 \mathrm{~m}$ de diámetro en la que se realizaron intensas tareas de molienda de los minerales auríferos extraídos en el lugar, según lo evidencian la presencia de al menos seis grandes instrumentos de molienda (marayes), y abundante mineral molido (figs. 3 y 4). El hallazgo por parte del equipo dirigido por el arqueólogo Hugo Yacobaccio de cerámica inka en el valle de Coyahuayma, nos permite suponer que las tareas mineras habrían comenzado en época prehispánica (Yacobaccio, com. pers. 2007). Los instrumentos de molienda mencionados, de morfología claramente prehispánica (aunque, por su gran eficiencia, también fueron utilizados en los primeros años de la Colonia), refuerzan la idea de una explotación temprana del oro local, luego indudablemente continuada durante época colonial.

\section{Hallazgos de época colonial}

Las evidencias que pueden adscribirse tentativamente al período colonial se encuentran en las tres grandes áreas de la región bajo estudio: 1) Fundiciones y Santo Domingo, 2) el sector sur de la cuenca de Pozuelos, y 3) el valle de Coyahuayma y la porción superior del río Rosario. Éstas presentan características propias en cada lugar pero a modo general pueden dividirse en dos grupos: aquellas relacionadas a la explotación aurífera y las vinculadas al proceso de fundición de metales, posiblemente argentíferos. Es necesario resaltar que resulta sumamente difícil asignar una cronología a las evidencias de explotaciones auríferas. En nuestro caso, hemos basado nuestras estimaciones provisorias en las características constructivas y de conservación de los pocos refugios asociados a los pozos, trincheras y socavones, ya que no hemos hallado material diagnóstico de temporalidad en ninguno de ellos. Existe la posibilidad, sin embargo, de que las explotaciones que ahora hemos considerado coloniales daten en realidad de época prehispánica o de época republicana temprana.

En el área de Fundiciones y Santo Domingo se han registrado cinco sitios con evidencias de prácticas minero-metalúrgicas: Santo Domingo 1, Laguna de Santo Domingo 7 y Laguna Pampa Colorada 1, dedicados al

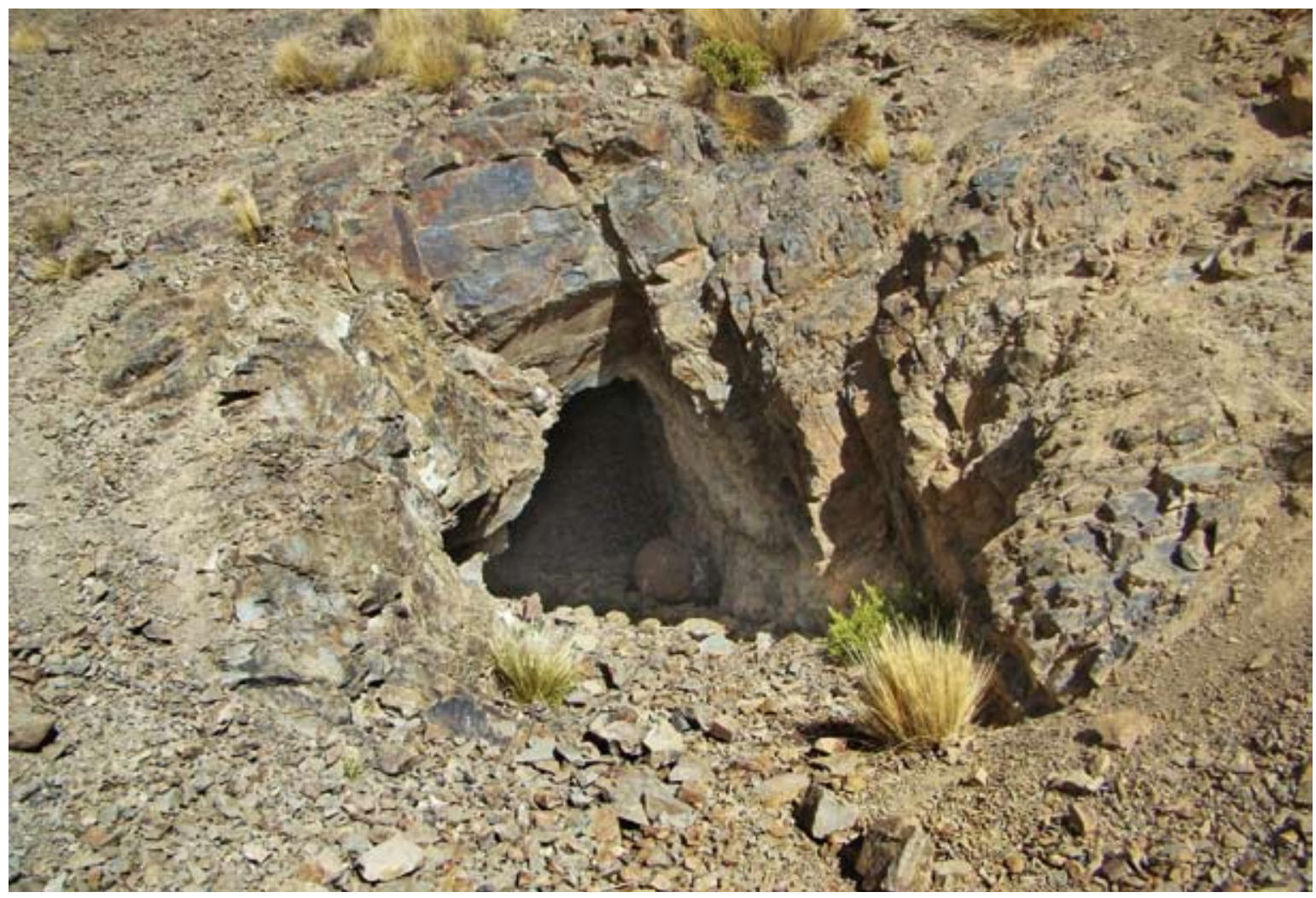

Figura 2. Rosario de Coyahuayma. Socavón para explotación de oro en veta.

Figure 2. Rosario de Coyahuayma. Shaft for mining a gold vein. 


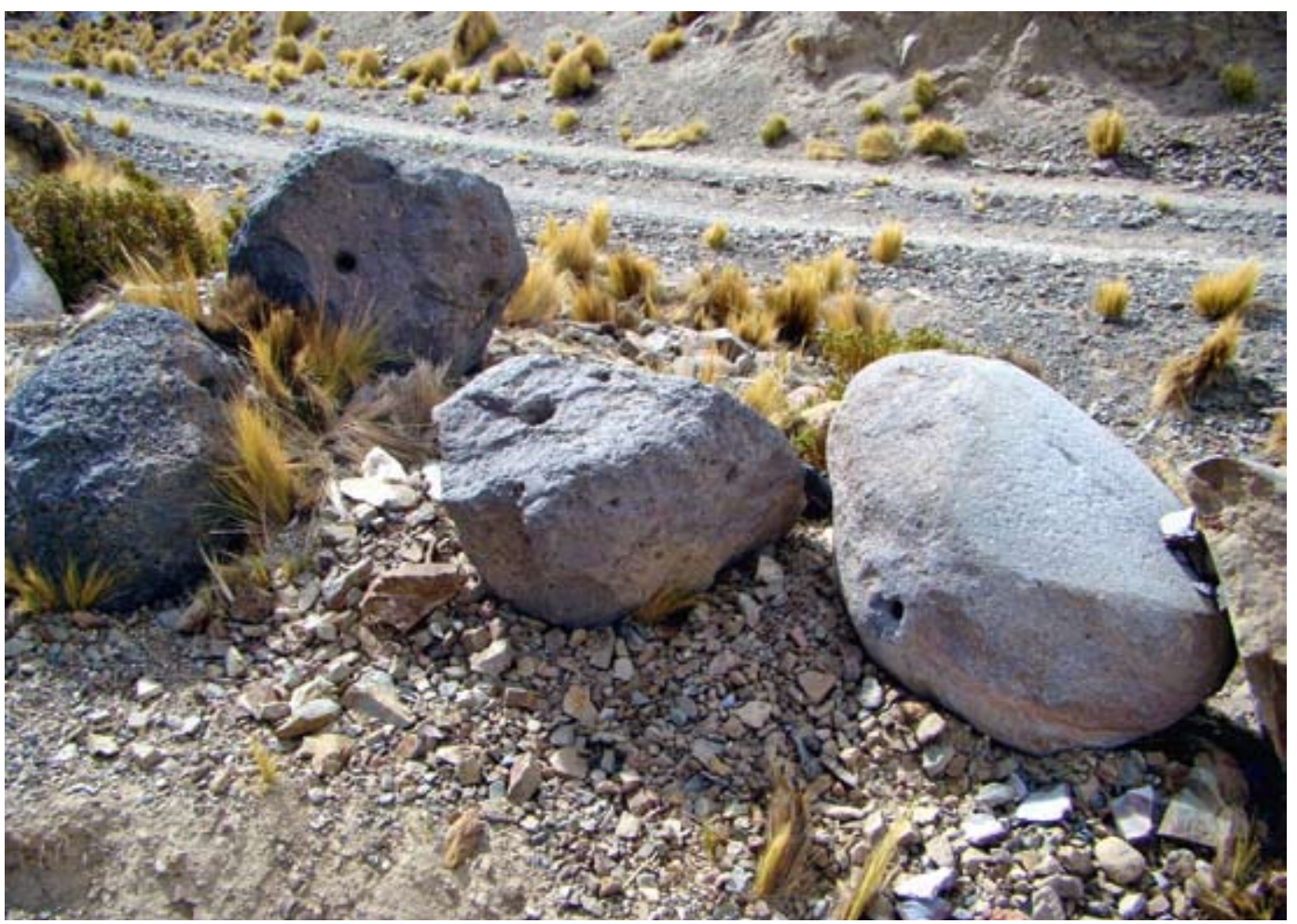

Figura 3. Rosario de Coyahuayma. Elementos activos de marayes.

Figure 3. Rosario de Coyahuayma. Active elements from grinding stones.

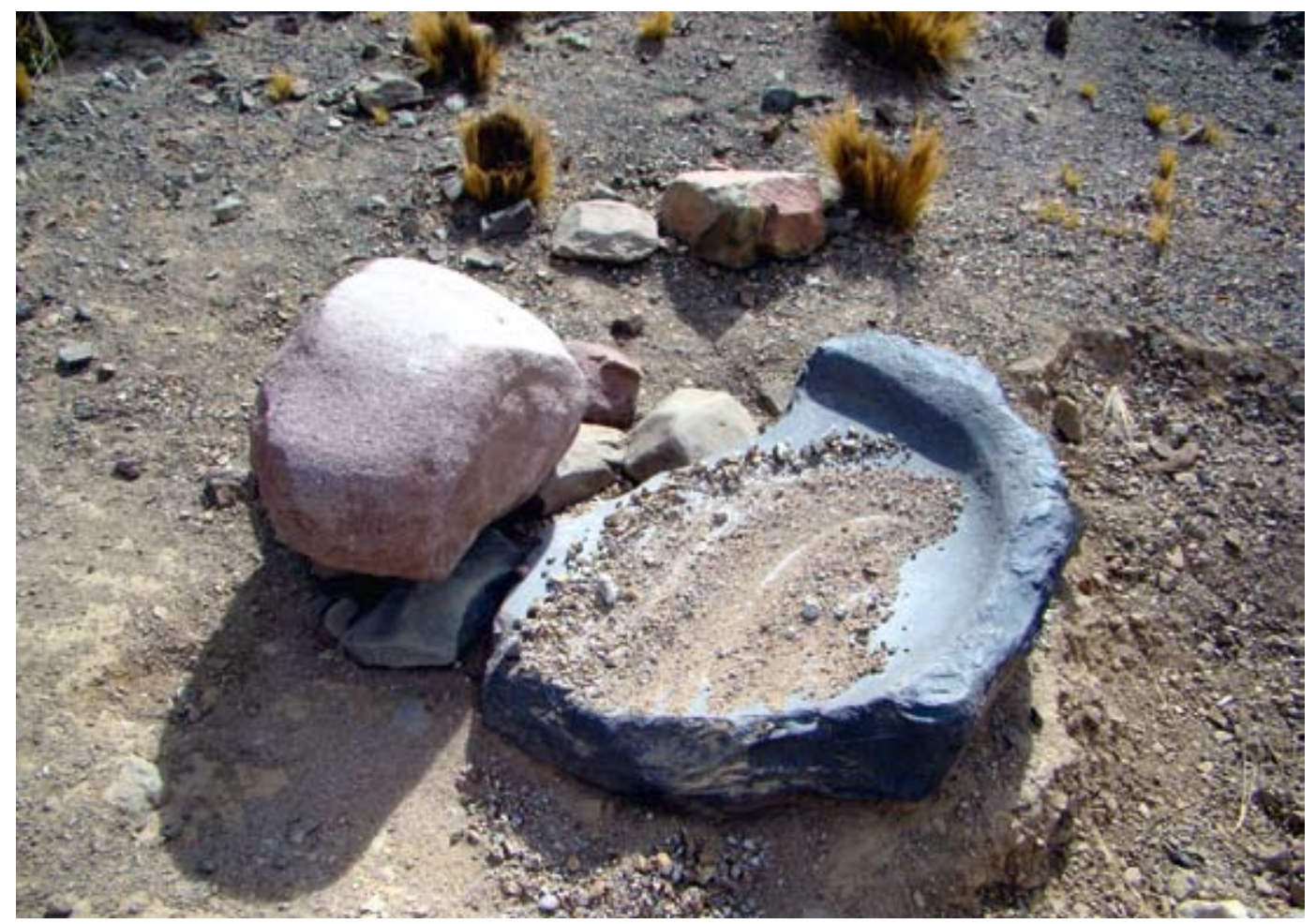

Figura 4. Rosario de Coyahuayma. Base de maray.

Figure 4. Rosario de Coyahuayma. Base of a grinding stone. 
lavado de oro, y Fundiciones 1 y 2, en el abra homónima, donde se ubican complejos mineros con hornos de fundición parcialmente conservados.

Santo Domingo 1. En este sitio se ha registrado una serie de trincheras de gran longitud para la extracción de sedimento aurífero para su lavado y algunas estructuras asociadas, en un área de unos 300 m de diámetro (fig. 5). Uno de los recintos, de planta circular y 1,9 $\mathrm{m}$ de diámetro se encuentra casi completamente conservado y presenta un techo en falsa bóveda construido con lajas dispuestas horizontalmente y argamasa. Dadas sus características es muy posible que haya sido el refugio de un minero habitado únicamente durante la época de laboreo. Dos de las demás estructuras asociadas son de grandes dimensiones, mientras que una de planta subcircular alcanza unos $2 \mathrm{~m}$ de diámetro. Ninguna de ellas ha sido techada. En el área se observó, además, el componente pasivo de un instrumento de molienda o maray utilizado en el tratamiento del mineral y numerosas acumulaciones de rocas.
Laguna Pampa Colorada 1. Las evidencias registradas aquí no difieren mucho de las de Santo Domingo 1. Se observaron también trincheras para el lavado de oro, excavadas en el sentido de la pendiente, de aproximadamente $3 \mathrm{~m}$ de ancho, dispuestas en un área de unos 100 m de diámetro. Además, se registró una estructura circular, de 1,5 m de diámetro interno, con muros construidos con lajas dispuestas en posición horizontal, con argamasa, y falsa bóveda (fig. 6). Se trataría, como en el caso anterior, de un refugio temporal. Sin embargo, a diferencia de aquél, en este caso no presenta vano de acceso, sino que se ingresa a la estructura a través de una abertura localizada en la parte superior.

Laguna Santo Domingo 7. Se trata de una estructura de planta subcircular de unos $2 \mathrm{~m}$ de diámetro con muros construidos con roca y argamasa. Sin dudas se trataba de un recinto techado. Junto a él se encuentran unas pocas trincheras similares a las ya descritas, y algunos pozos de aproximadamente 2 por $3 \mathrm{~m}$, de forma rectangular, para extracción de sedimento aurífero.

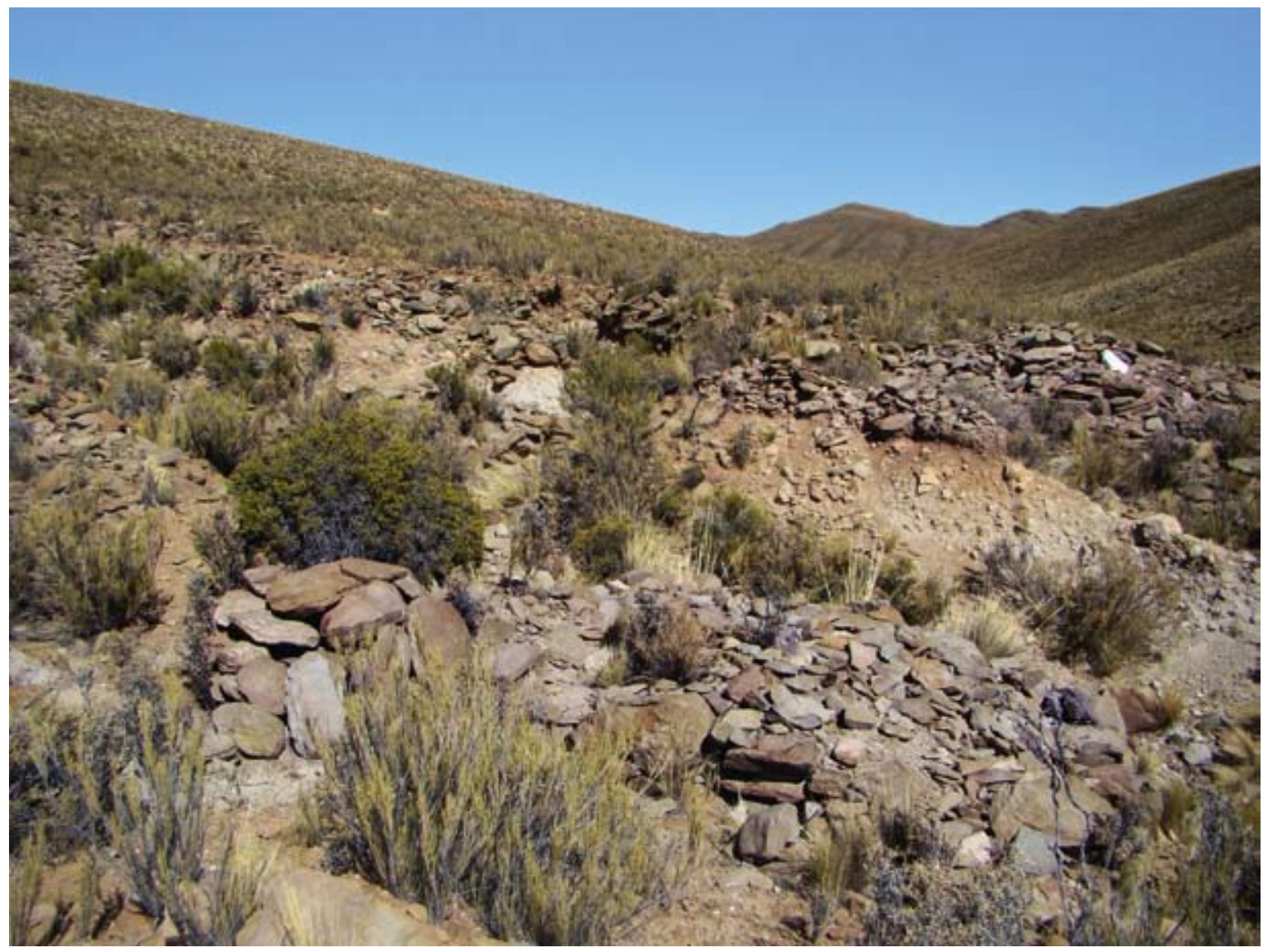

Figura 5. Santo Domingo 1. Pozos y trincheras para explotación aurífera

Figure 5. Santo Domingo 1. Shafts and pits for gold extraction. 


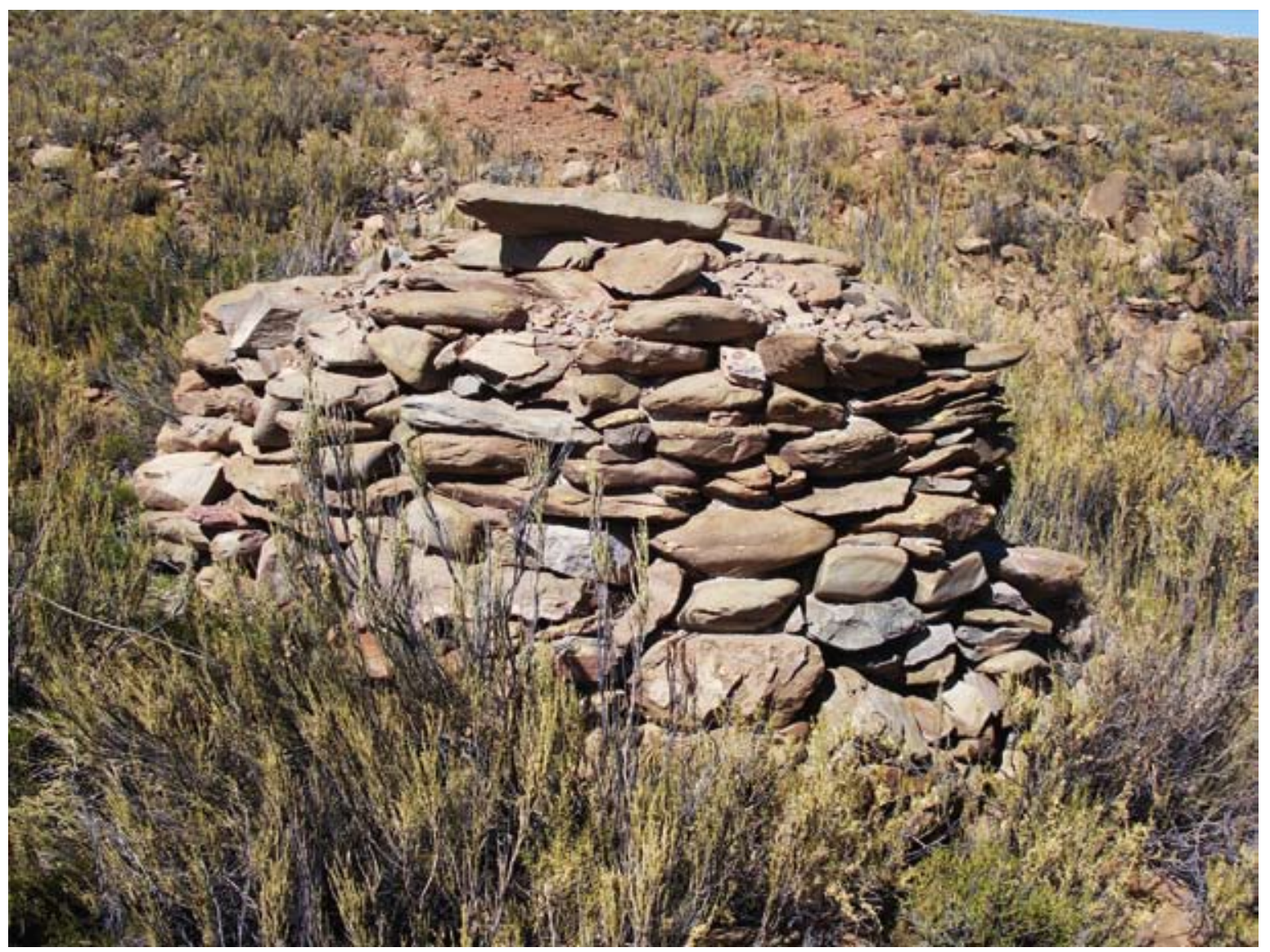

Figura 6. Laguna Pampa Colorada 1. Refugio. Figure 6. Laguna Pampa Colorada 1. Shelter.

Fundiciones 1. En el paraje de Fundiciones, a metros del actual campamento minero de Mina Chinchillas se encuentra un complejo, denominado por nosotros Fundiciones 1. El mismo consiste en cuatro hornos de fundición, construidos con rocas y alineados al pie de una ladera, paralelos a un curso de agua temporario. Uno de ellos se encuentra completamente conservado, con una bóveda de aproximadamente $3 \mathrm{~m}$ de diámetro, una caja de fuego prismática y una chimenea cónica (figs. 7 y 8). Presenta orificios de respiradero, bocas laterales y una abertura circular central en su bóveda. Sus características estructurales nos permiten clasificarlo como un horno de reverbero. El segundo horno es levemente menor y sólo se conserva parcialmente la bóveda y la chimenea (fig. 9). Los hornos 3 y 4 , de menor tamaño, sólo conservan sus cimientos, aunque parecerían ser del mismo tipo que los mayores.

A diferencia del primero, los otros tres hornos se encuentran vinculados por una pirca que une los trayectos que van de un horno al siguiente. Las rocas que conforman estos muros presentan signos de termoalteración y vitrificado, como aquellas que forman parte de los hornos. Aún no se ha podido establecer la funcionalidad de la misma.

Más allá de las estructuras de combustión, sólo se recuperaron escorias metalúrgicas y algunos minerales metalíferos en superficie. Análisis efectuados sobre estos desechos de fundición han permitido concluir que estos hornos se utilizaron para la fundición de minerales de plata y plomo, probablemente extraídos del yacimiento cercano, llamado actualmente mina Chinchillas (Becerra 2009; Becerra et al. 2010, en prensa).

Fundiciones 2. Este segundo complejo se encuentra a $2,5 \mathrm{~km}$ de distancia del anterior, en línea recta. Consiste en cinco hornos de similar construcción, con el diseño de caja de fuego, bóveda y chimenea presente en el complejo 1. Sin embargo, se observan ciertas características particulares. En este caso, tres de esos hornos se encuentran en el interior de un recinto preparado para albergarlos (figs. 10 y 11). Esta estructura, de forma rectangular, posee en uno de sus muros siete 


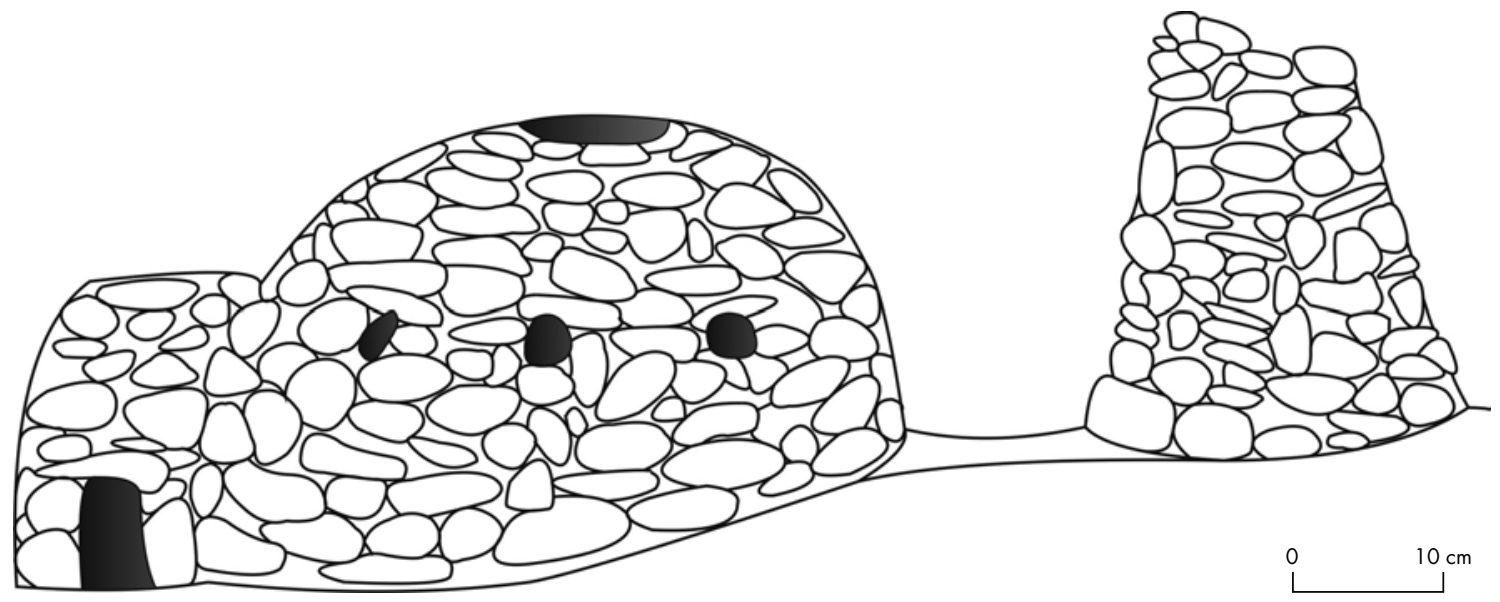

Figura 7. Fundiciones 1. Horno de reverbero (dibujo de J. Pérez Pieroni). Figure 7. Smelter 1. Reverbatory furnace (drawing by J. Pérez Pieroni).

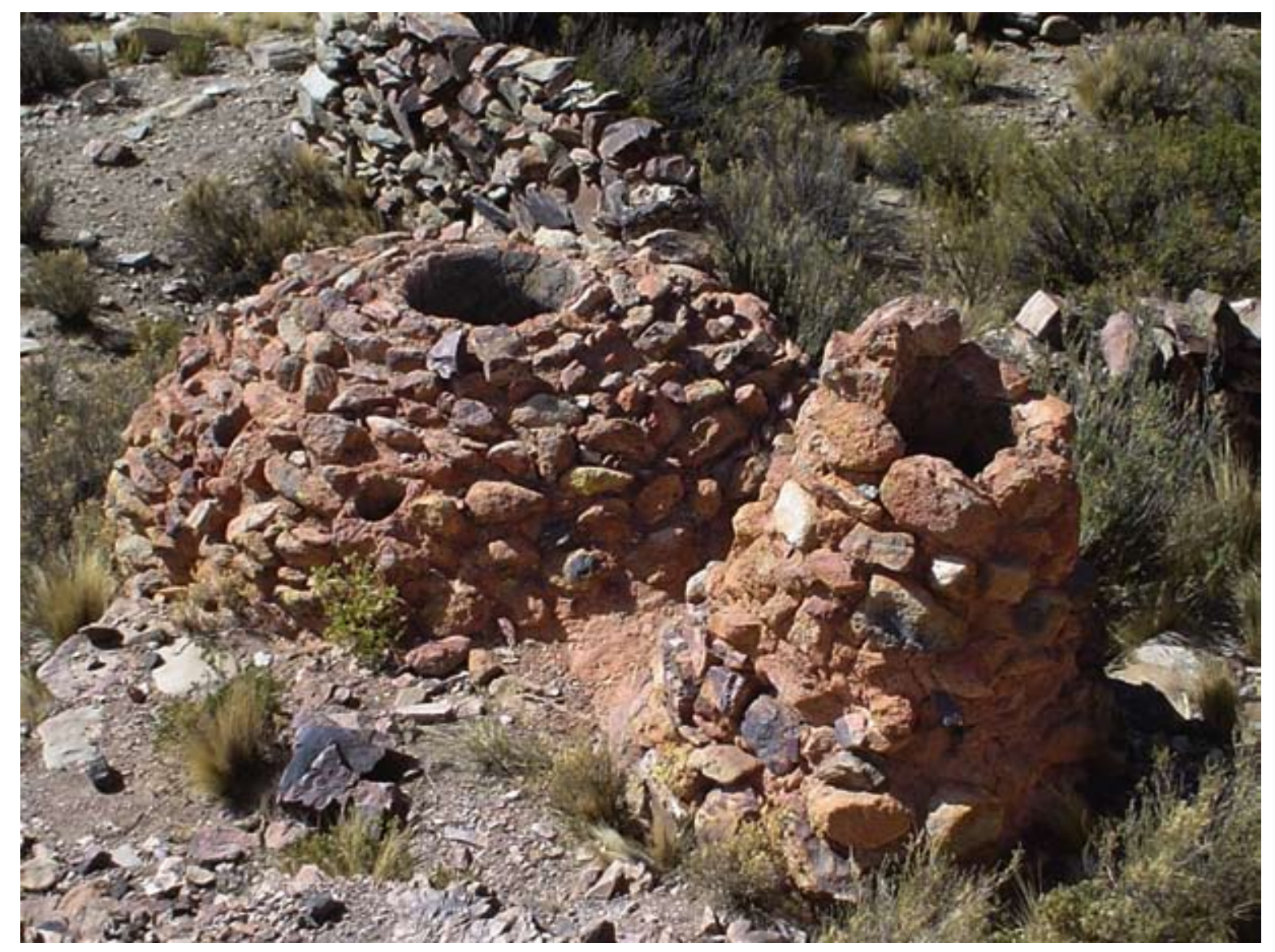

Figura 8. Fundiciones 1. Horno de reverbero.

Figure 8. Smelting works 1. Reverbatory furnace. 


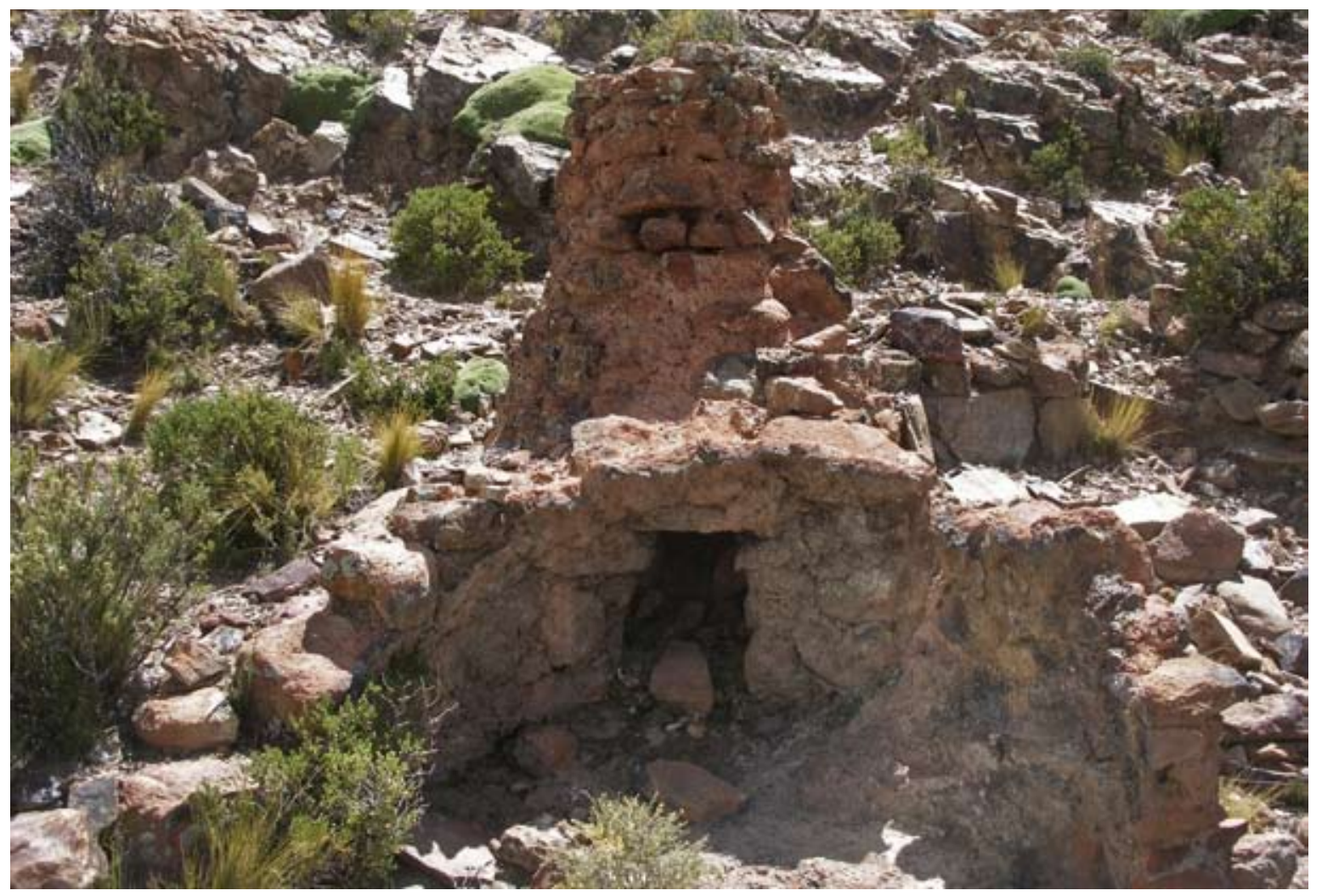

Figura 9. Fundiciones 1. Parte de horno de reverbero.

Figure 9. Smelting works 1. Part of a reverbatory furnace.

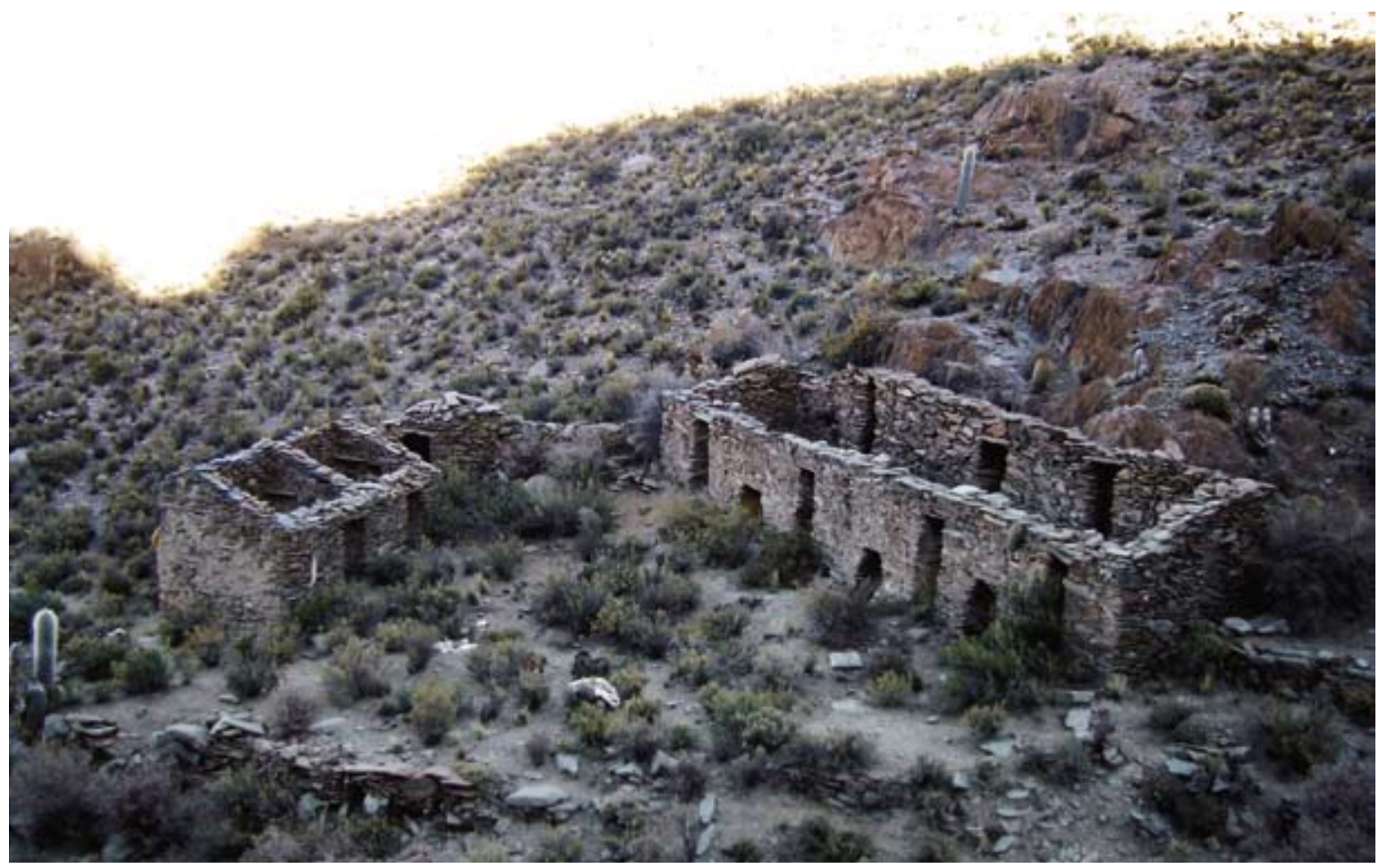

Figura 10. Fundiciones 2. La construcción de la derecha es la que aloja los hornos de fundición.

Figure 10. Smelting works 2. The building on the right houses the smelter furnaces. 


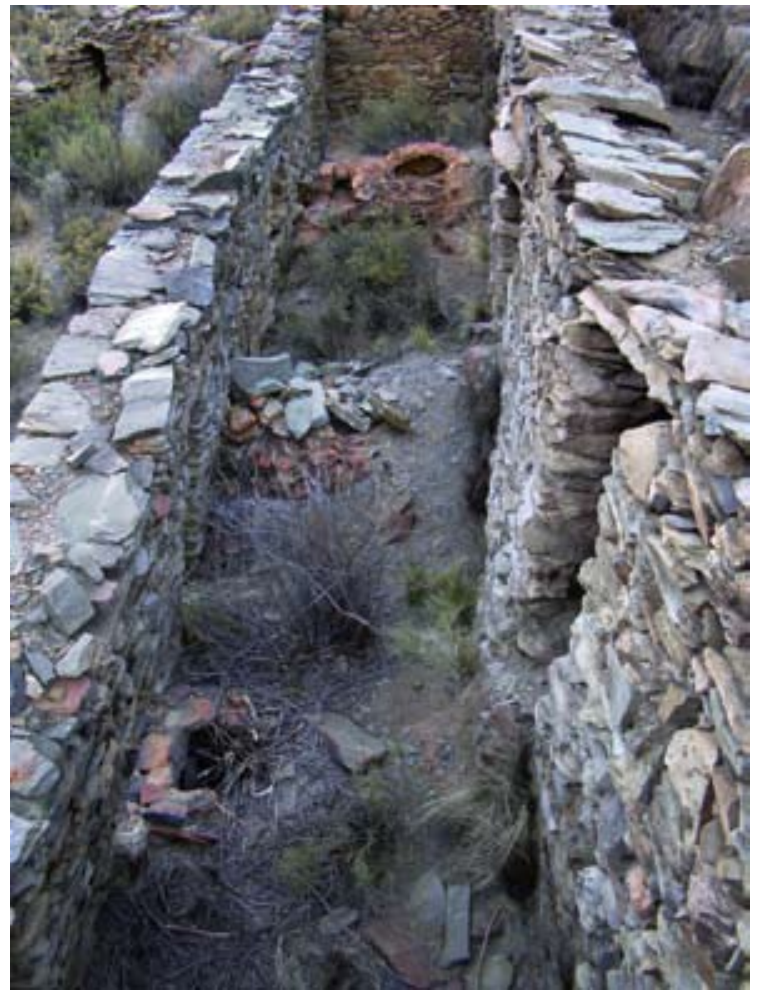

Figura 11. Fundiciones 2. Se observan los tres hornos de reverbero en el interior del recinto.

Figure 11. Smelting works 2. The three reverbatory furnaces can be seen inside the enclosure.

vanos rectangulares con dintel: tres menores (anchos y bajos), en el lugar donde se encuentra la caja de fuego de cada uno de los hornos y cuatro mayores (altos y angostos), intercalados con los anteriores. En el lado opuesto se observan tres vanos, que coinciden con las chimeneas de dichos hornos. Esto hace pensar que la emisión de los gases se habría dado principalmente fuera de la estructura. Sin embargo, lo que resulta extraño es que la construcción de este recinto fue realizada de modo que las chimeneas y estos vanos se encuentran inmediatamente junto a un afloramiento rocoso de altura considerable que dificultaría la salida de dichas emisiones. En él, al contrario de lo esperable, no se observan evidencias de termoalteración. Por último, en uno de los muros laterales del recinto, se localiza otro vano.

En la argamasa de las paredes de la estructura se observan fragmentos de escoria de aspecto vítreo. Los hornos se encuentran parcialmente conservados y colmados de sedimento, ubicados a distancias de 2,6 y 1,6 $\mathrm{m}$ de cada uno, respectivamente. Mientras que el horno 1 presenta una bóveda de 1,6 m de diámetro externo, la del horno 2, es de $1 \mathrm{~m}$.
Cerca de esta estructura se encuentra otra conformada por dos recintos cuadrangulares que comparten uno de sus muros, con un vano cada uno que comunica con el exterior. Ambas estructuras están construidas para sostener un techo a "un agua" y no presentan estructuras de combustión en su interior. Por sus características se tratarían de recintos habitacionales.

A unos $4 \mathrm{~m}$ de la primera estructura se localiza el cuarto horno, de mayores dimensiones $(2,5 \mathrm{~m}$ de diámetro externo y $4,4 \mathrm{~m}$ de longitud total). El mismo está conformado, como los anteriores, por una caja de fuego, bóveda y chimenea conectados entre sí, y presenta derrumbes de algunos de sus muros. El quinto horno se localiza a $8 \mathrm{~m}$ en línea recta de este último. Es el de menor tamaño con una bóveda de $0,8 \mathrm{~m}$ de diámetro externo. Se encuentra completo y, a diferencia de los anteriores, no presenta vitrificado ni en el interior de la bóveda ni en la chimenea.

En el Sur de Pozuelos, por su parte, se han registrado evidencias de prácticas de fundición y de lavado de oro en los sitios mencionados a continuación.

Pan de Azúcar 1 y 26. En el cerro Pan de Azúcar se han hallado evidencias de prácticas de fundición en dos sectores: un horno parcialmente conservado en una ladera (Pan de Azúcar 26), y, al pie del cerro, en la ladera opuesta, bases de hornos y concentraciones de escorias metalúrgicas (Pan de Azúcar 1).

El horno mencionado no presenta estructuras asociadas directamente con él. Presenta una bóveda de $2 \mathrm{~m}$ de diámetro, cuyos muros están parcialmente derrumbados y se observan evidencias de la presencia de una posible caja de fuego y de una chimenea conectada por un conducto superficial, también destruido en parte (fig. 12). Como el resto de los hornos de estas características, presenta una abertura circular superior y una lateral sellada, además de las que comunicarían a las otras partes del horno. No se observan orificios de respiración.

En el sector de pie del cerro, en las proximidades al pueblo actual de Pan de Azúcar, se observa un área de un diámetro aproximado de $20 \mathrm{~m}$, distinguible por la coloración oscura y rojiza de la superficie, debida a la presencia de escoria metalúrgica, minerales y fragmentos de hornos tapizando el sector (fig. 13). Los habitantes del actual pueblo de Pan de Azúcar denominan al lugar como el "escorial". En este sector se registraron dos bases de hornos delimitados por rocas rojizas termoalteradas. Una de las bases parecería haber conformado parte de la entrada lateral del horno, mientras que la segunda es menos definida y forma únicamente una línea en forma de "L". 


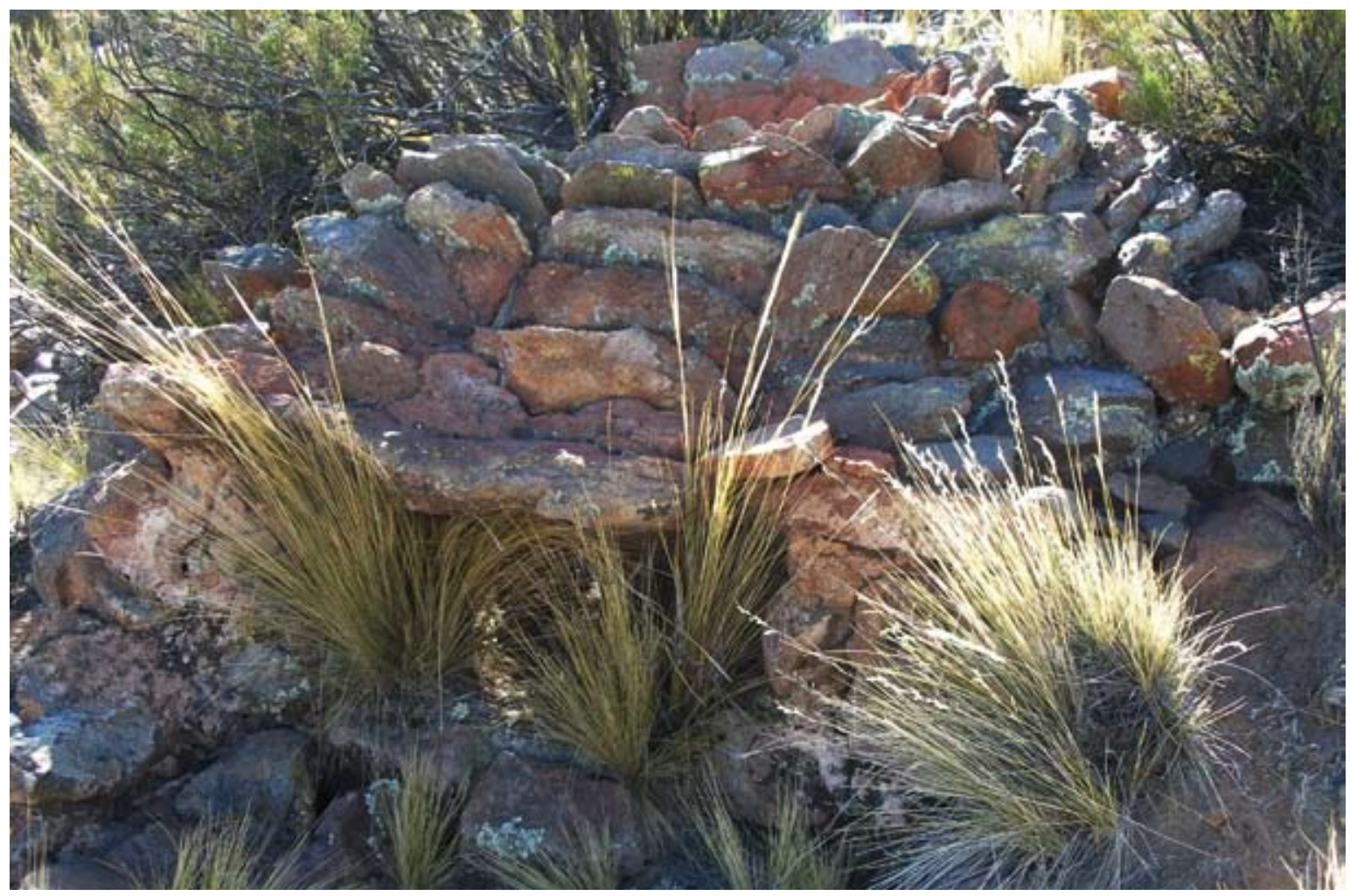

Figura 12. Pan de Azúcar 26. Horno de fundición. Figure 12. Pan de Azúcar 26. Smelting furnace.

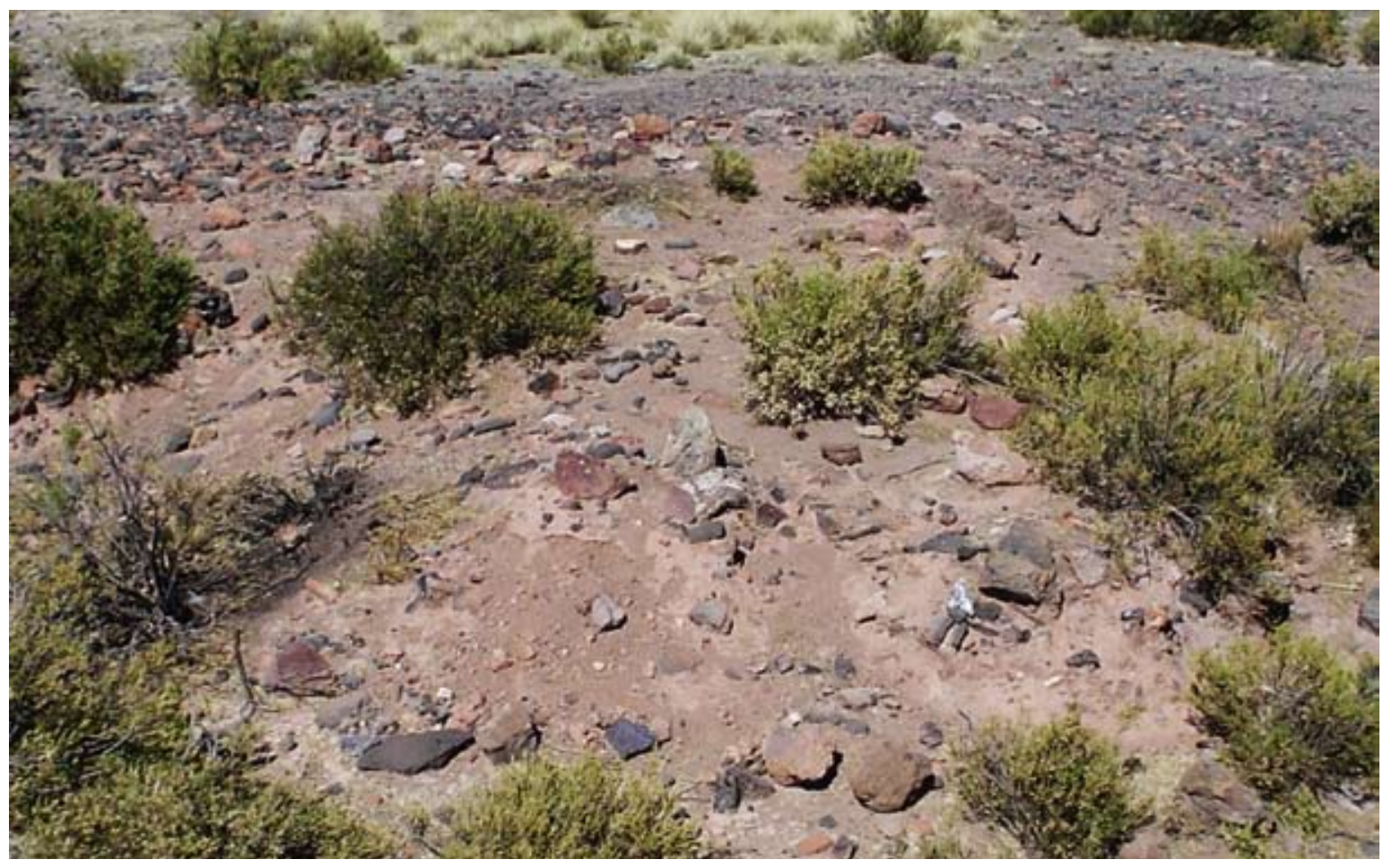

Figura 13. Pan de Azúcar 1. Base de horno y escorial.

Figure 13. Pan de Azúcar 1. Base of a furnace and slag. 
Chajarabuaico 25. En la Quebrada de Chajarahuaico también se han registrado los restos de un horno de fundición a la vera de un curso de agua (fig. 14). Se observan los cimientos de una estructura prismática de 2 por 0,6 $\mathrm{m}$ aproximadamente, con una altura conservada de $0,6 \mathrm{~m}$. No se logra identificar la forma y el funcionamiento de este horno, pero podría inferirse que era de mayores dimensiones de las conservadas, ya que en uno de sus laterales se observa sedimento rojizo y rocas termoalteradas que podrían demarcar el área ocupada por la estructura completa. Junto a esta estructura rectangular conservada se encuentra una queñoa de más de $3 \mathrm{~m}$ de altura, cuyas raíces han crecido por sobre los cimientos. Esto probaría que su crecimiento fue posterior al funcionamiento del horno y podría indicarnos su antigüedad mínima. La misma ha sido estimada en más de 300 años en base a las características del ejemplar y a las condiciones ambientales en las que ha crecido.

Al lado de los cimientos del horno se emplazan dos estructuras semicirculares, en cuyas paredes se observan rocas termoalteradas, algunas con evidencia de vitrificado.

En la otra margen del río, y a unos $25 \mathrm{~m}$ del anterior, se observa una acumulación de rocas termoalteradas, posiblemente cimientos de otro horno de fundición. Destaca en este caso la gran cantidad de escoria dispersa en los alrededores y especialmente concentrada junto a un afloramiento rocoso a tan sólo unos metros de la base del horno. En las cercanías de este horno se observa también una estructura rectangular y un recinto pequeño circular. En la parte superior de la ladera se registraron también recintos rectangulares, dos de los cuales fueron excavados completos. Uno data de época prehispánica tardía y el otro de época colonial (Angiorama 2009b).

Cabecera de río Herrana 6-7. Este sitio consiste en tres recintos habitacionales de plantas circulares construidos con rocas y argamasa, con techo en falsa bóveda (fig. 15). Uno de ellos fue edificado aprovechando un farallón como parte del muro, otro presenta un nicho construido

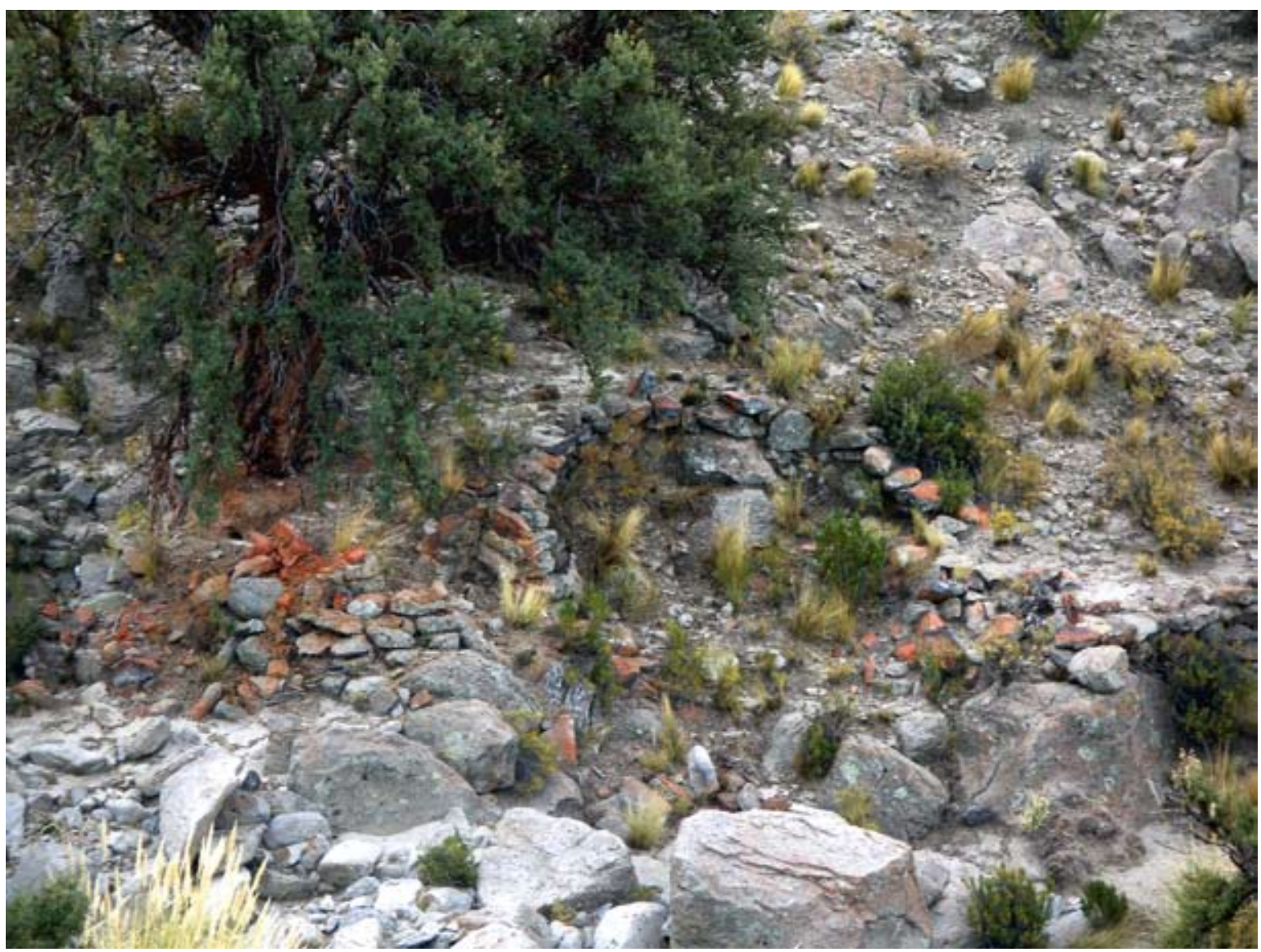

Figura 14. Chajarahuayco 25. Horno de fundición. Junto a él se observa la queñoa mencionada en el texto.

Figure 14. Chajarabuayco 25. Smelting furnace. Beside it is the Queñoa tree (Polylepis tarapacana) mentioned in the text. 


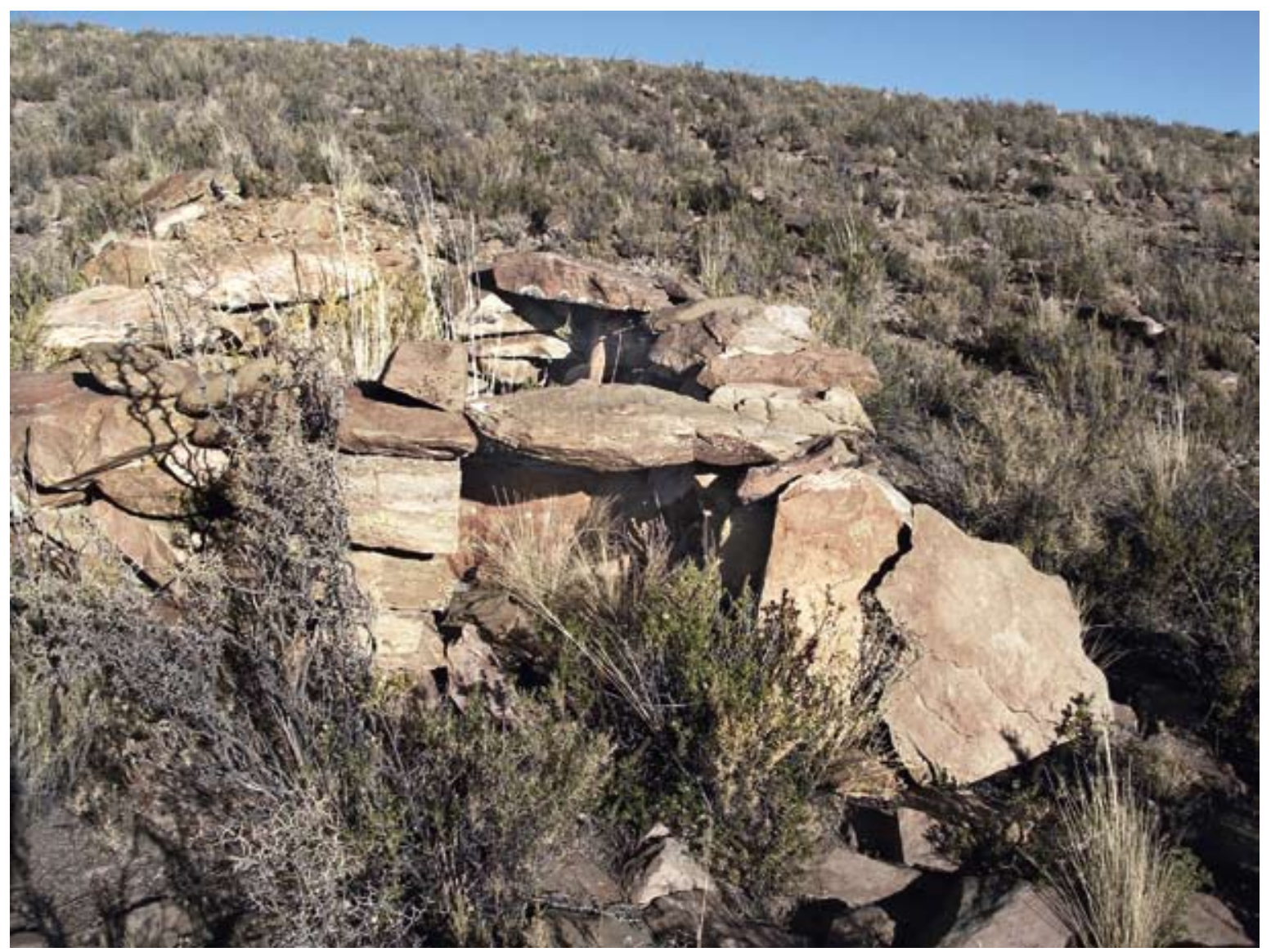

Figura 15. Cabecera de Río Herrana 6-7. Refugio.

Figure 15. Headwaters of Río Herrana 6-7. Rock shelter.

en el muro. Todos alcanzan un diámetro de entre 1,8 y $2 \mathrm{~m}$. Los recintos están vinculados a trincheras excavadas para la extracción de sedimento aurífero, de 1 a $2 \mathrm{~m}$ de ancho y de hasta $50 \mathrm{~m}$ de largo, distribuidas por un área de unos $200 \mathrm{~m}$ de diámetro (fig. 16). En algunos casos se observan muros de contención en las mismas y grandes acumulaciones de rocas junto a ellas.

Río Lopiara 8. En este sitio se han registrado concentraciones de rocas asociadas a prácticas de lavado de oro a la vera de un río temporal, y varias trincheras similares a las ya descritas. También se registró un muro doble con relleno de $4 \mathrm{~m}$ de longitud que llega hasta la margen del río. En las cercanías se observan estructuras rectangulares y circulares de dimensiones varias, construidas con rocas y argamasa, pero más modernas.

Jara Loma 3. Consiste en un área que presenta una gran cantidad de trincheras para el lavado de sedimento aurífero, algunas de unos $50 \mathrm{~m}$ de longitud y $2 \mathrm{~m}$ de ancho (fig. 17). Se observa una senda en parte calzada con rocas y un muro doble con relleno de aproximadamente $1 \mathrm{~m}$ de altura construido a manera de dique en un curso de agua de escorrentía. Se registraron también algunas grandes acumulaciones de rocas. El sitio se encuentra a unos $400 \mathrm{~m}$ de un puesto habitado actualmente durante parte del año, de manera que cabe la posibilidad de que el pequeño dique date de tiempos más modernos.

Por último, en Coyahuayma, hemos registrado evidencias minero-metalúrgicas en dos sectores: Rosario de Coyahuayma y Casablanca.

Rosario de Coyahuayma. Como dijimos, en los alrededores de Rosario de Coyahuayma se observa una enorme cantidad de pozos de extracción de sedimento aurífero y algunos socavones para la explotación del oro en veta. Teniendo en cuenta la iglesia de época colonial construida junto a algunos de ellos y los restos de viviendas probablemente coloniales que se conservan en el valle, suponemos que la mayoría de las evidencias de explotación minera datarían de aquella época. Es más, quizás 


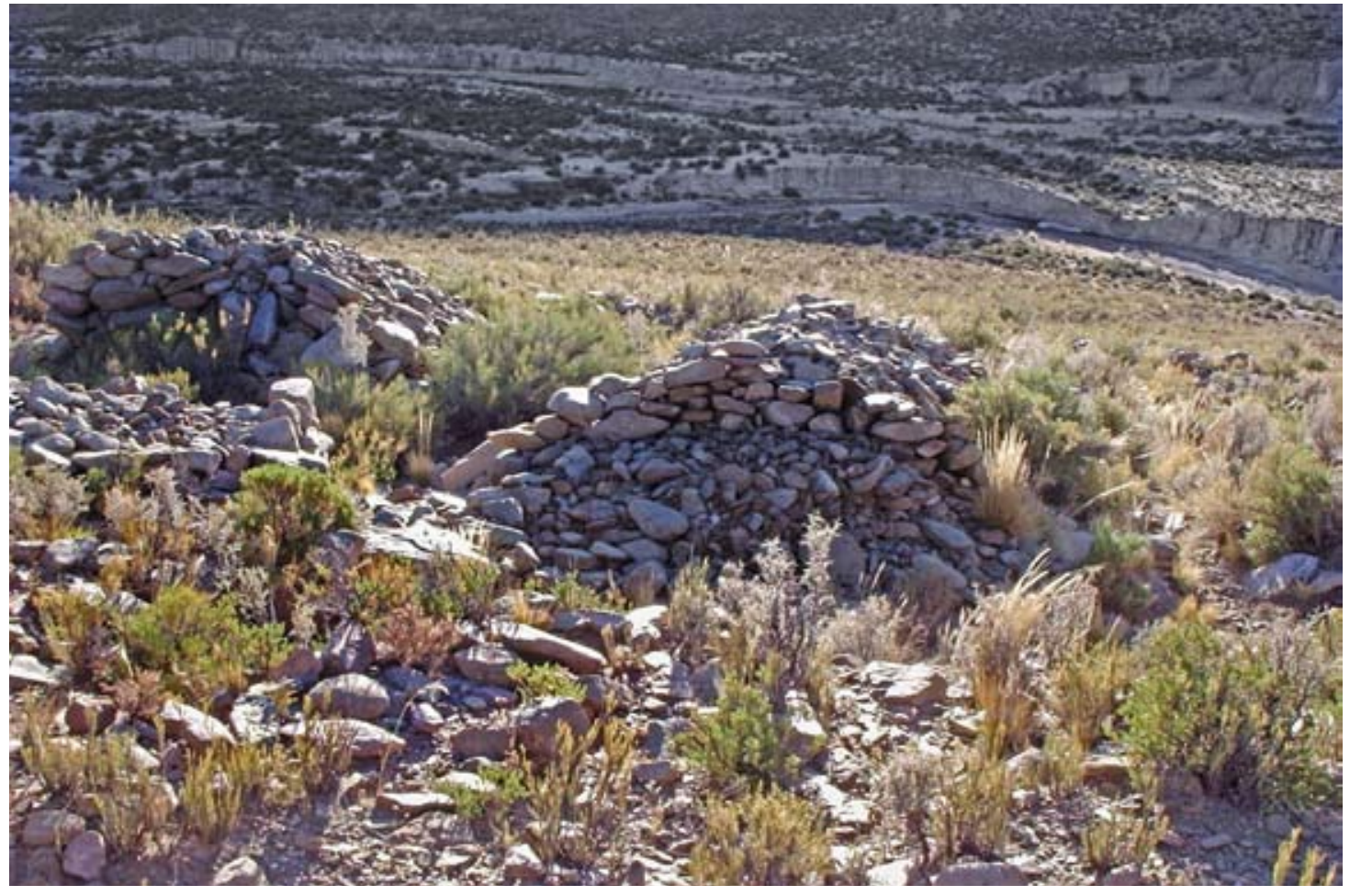

Figura 16. Cabecera de Río Herrana 6-7. Pozos para explotación aurífera y acumulaciones de rocas.

Figure 16. Headwaters of Río Herrana 6-7. Shafts for mining gold deposits and rock piles.

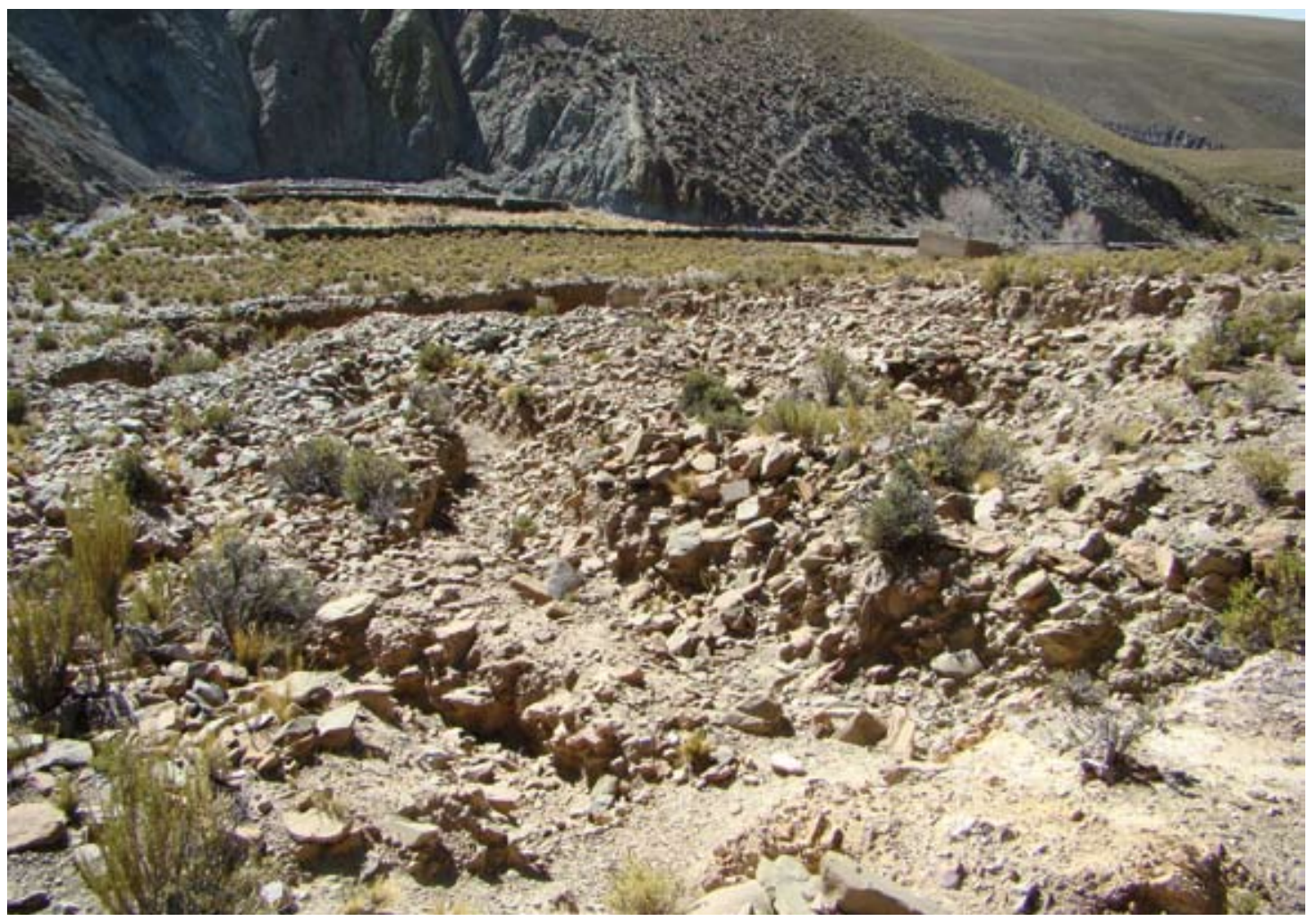

Figura 17. Jara Loma 3. Pozos y trincheras para explotación aurífera.

Figure 17. Jara Loma 3. Shafts and trenches for gold mining. 
al menos algunos de los marayes registrados hayan sido utilizados durante las explotaciones coloniales.

Casablanca. Se encuentra a unos $5 \mathrm{~km}$ lineales de la localidad de Rosario de Coyahuayma, a ambas márgenes del río homónimo. En superficie se observa un complejo con estructuras apropiadas para el desarrollo de una gran variedad de actividades relacionadas con el proceso de obtención de metal a partir de sus menas: tratamiento de mineral (molienda, lavado, selección) y fundición (Angiorama 2003).

El complejo consta de dos sectores constructivos, complementarios entre sí. Uno de ellos concentra la mayoría de las estructuras, mientras que el otro, a $100 \mathrm{~m}$ de distancia, está integrado por tres hornos de fundición. En cuanto al primer sector, presenta recintos de piedra a ambos lados de un curso de agua, construidos aprovechando las paredes del cañadón como techo y cerramientos posteriores. A unos metros de estos recintos, se observa una estructura muy compleja, con muros conservados de dos tipos, uno con rocas planas blancas y otro con rocas subesféricas rojizas. Presenta vanos en arco, conformados por rocas colocadas de canto. Actualmente es utilizada como corral. Frente a este gran recinto se encuentra un conjunto de cinco marayes ubicados en un área de $10 \mathrm{~m}$ de diámetro. Son de forma trapezoidal, con una perforación en cada una de las caras laterales destinada a la sujeción de palos para moverlos durante la molienda de mineral (fig. 18). En este sector se localiza una plataforma de rocas dispuestas de forma horizontal a fin de lograr una superficie plana (fig. 19). A unos metros de ella se observa la base de un horno de fundición reconocible por la presencia de rocas termoalteradas. Según los habitantes del lugar, habría sido un horno de fundición de planta cuadrangular con una chimenea de varios metros de altura.

El complejo también presenta, a un costado de este sector de molienda y fundición, una estructura rectangular. Inmediatamente al lado de ésta se encuentra una plataforma de mayores dimensiones que la primera, cuyo perímetro está delimitado por rocas blancas dispuestas de canto. Se observa también un canal empedrado que

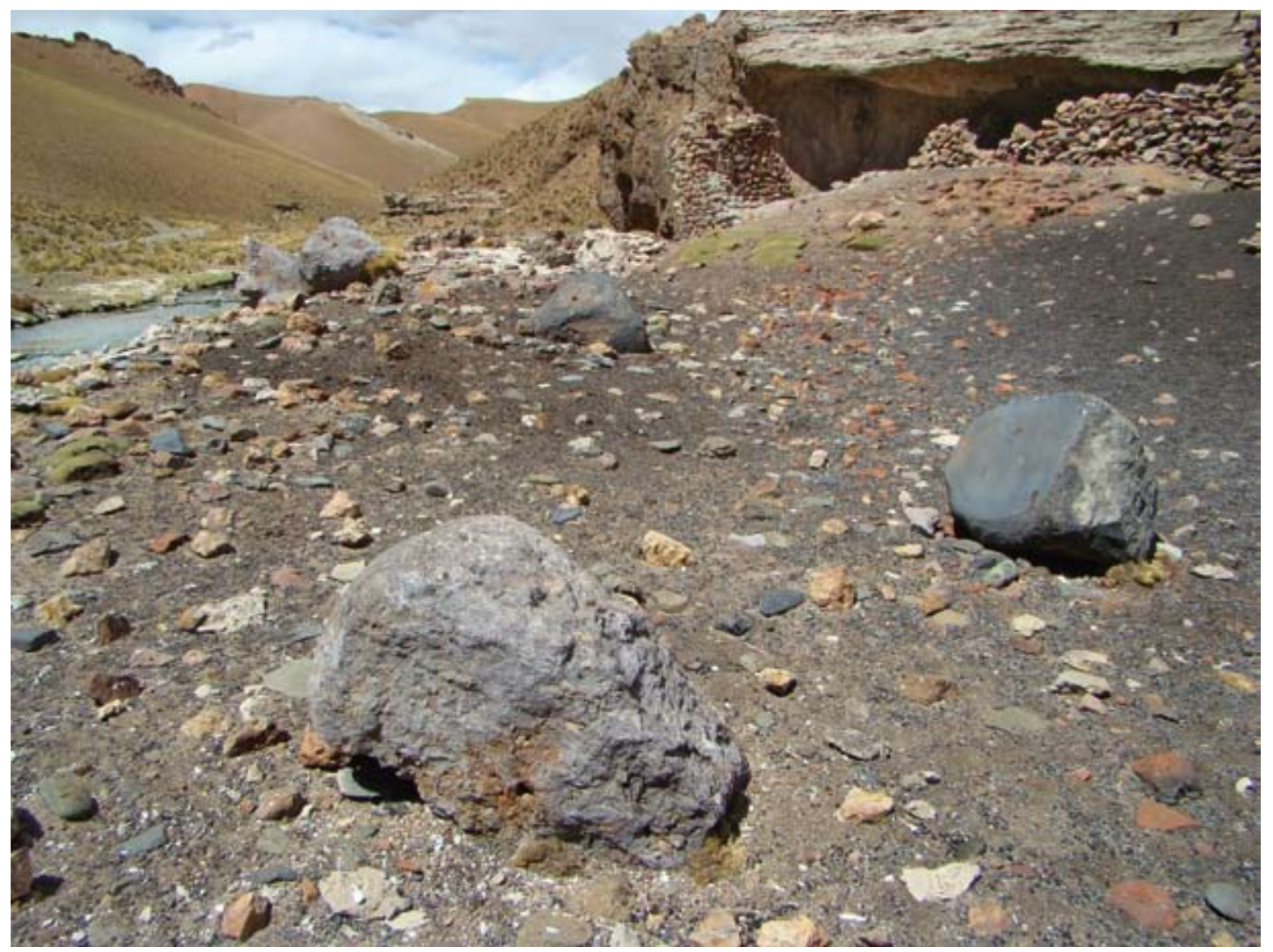

Figura 18. Casablanca. Marayes. Al fondo se observan algunas de las construcciones mencionadas en el texto.

Figure 18. Casablanca. Grinding stones. In the background are some of the structures mentioned in the text. 


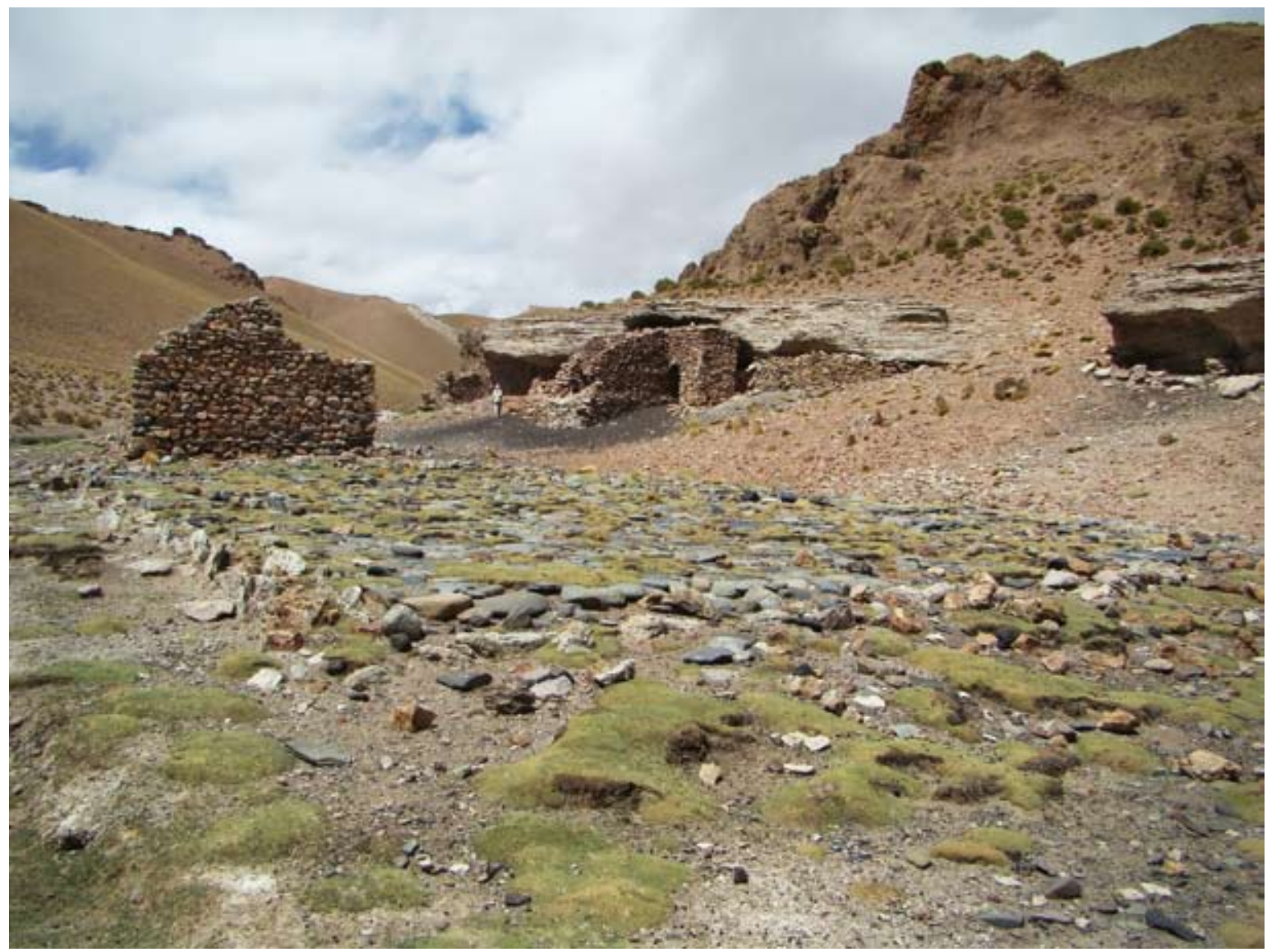

Figura 19. Casablanca. Plataforma empedrada. Al fondo se observan algunas de las construcciones mencionadas en el texto. Figure 19. Casablanca. Cobbled stone platform. In the background are some of the structures mentioned in the text.

debió conducir agua desde el río hasta cerca de esta gran plataforma.

En el segundo sector, en un área de $50 \mathrm{~m}$ de diámetro aproximadamente, se observaron los restos de al menos tres hornos de fundición, alineados al pie de una ladera. Se trata de hornos de paredes de piedra, con claras evidencias de termoalteración. Presentan planta circular, con techo abovedado y una abertura central subcircular (Angiorama 2003). El horno 1 se encuentra en mejor estado de conservación, con una bóveda de 2,5 $\mathrm{m}$ de diámetro externo y una altura de $1,25 \mathrm{~m}$, presentando tres conductos de ventilación y una abertura lateral cuadrangular (fig. 20). No se conserva la caja de fuego, ya que el sector adecuado para su ubicación se encuentra destruido, observándose una abertura trapezoidal derrumbada en parte. La chimenea se encuentra colapsada por sedimento, pero se conserva el canal de conexión entre la misma y la bóveda, conformado por lajas. La bóveda presenta además otro conducto rectangular de más de 1,2 m de longitud. Hasta el momento no se ha logrado identificar hacia dónde conduce, ya que desde el exterior no se distingue ninguna estructura debido a la depositación de sedimentos provenientes de sectores más altos de la ladera. En cuanto a los hornos 2 y 3, el estado de conservación no es bueno: sólo se observan las bóvedas colapsadas. En el caso del tercer horno, ésta presenta una abertura superior y una frontal con dintel, y un tamaño menor en comparación con el primero (1,6 m de diámetro externo) (fig. 21). Debido a la acumulación de sedimento en el interior y en el exterior, en estos hornos no se distingue el sistema de ventilación.

Según los informantes locales, allí se fundían minerales de plata extraídos del cerro Poques localizado en el límite con Chile. Las escorias metalúrgicas recuperadas se encuentran en proceso de análisis. 


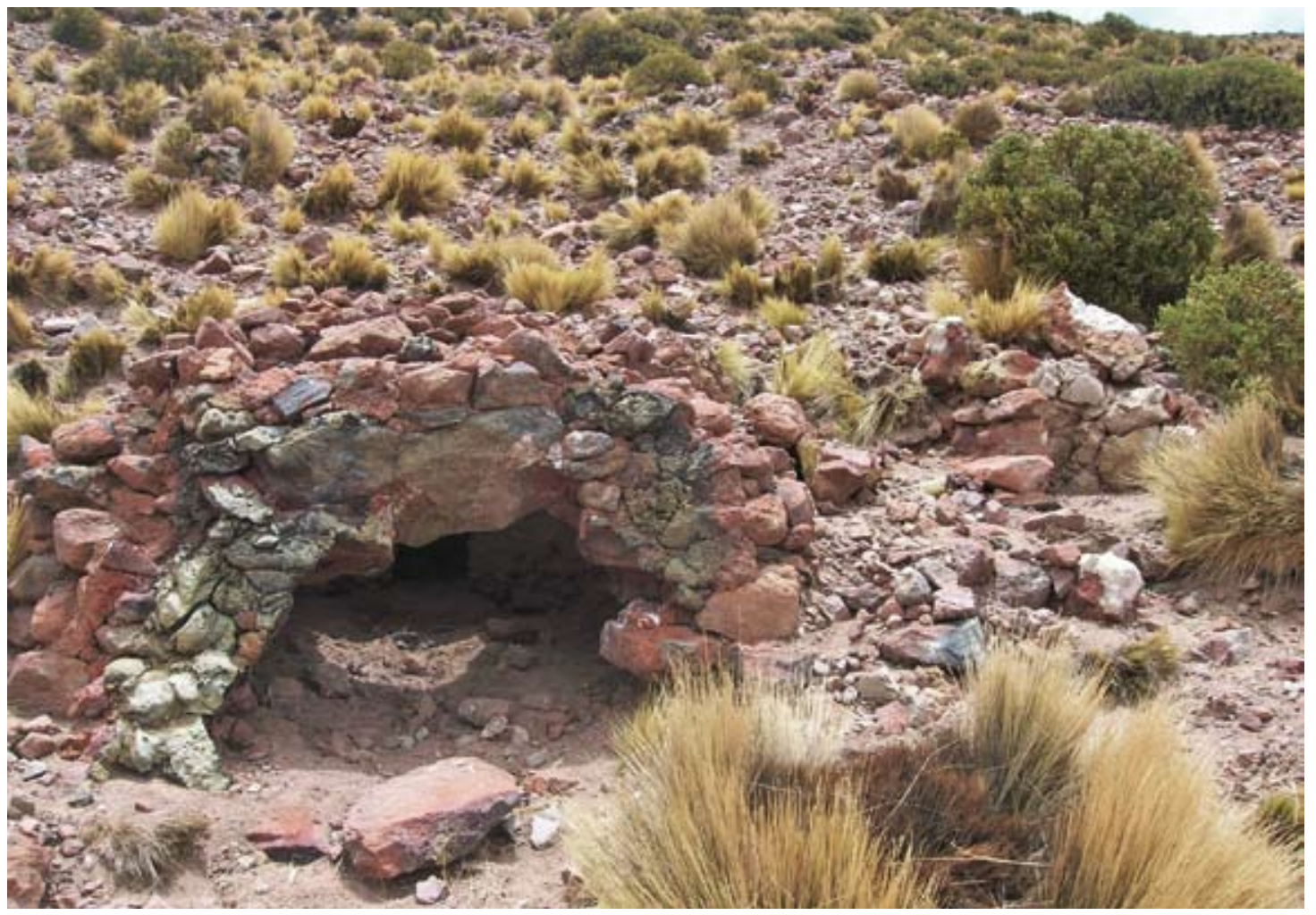

Figura 20. Casablanca. Horno de fundición.

Figure 20. Casablanca. Smelting furnace.

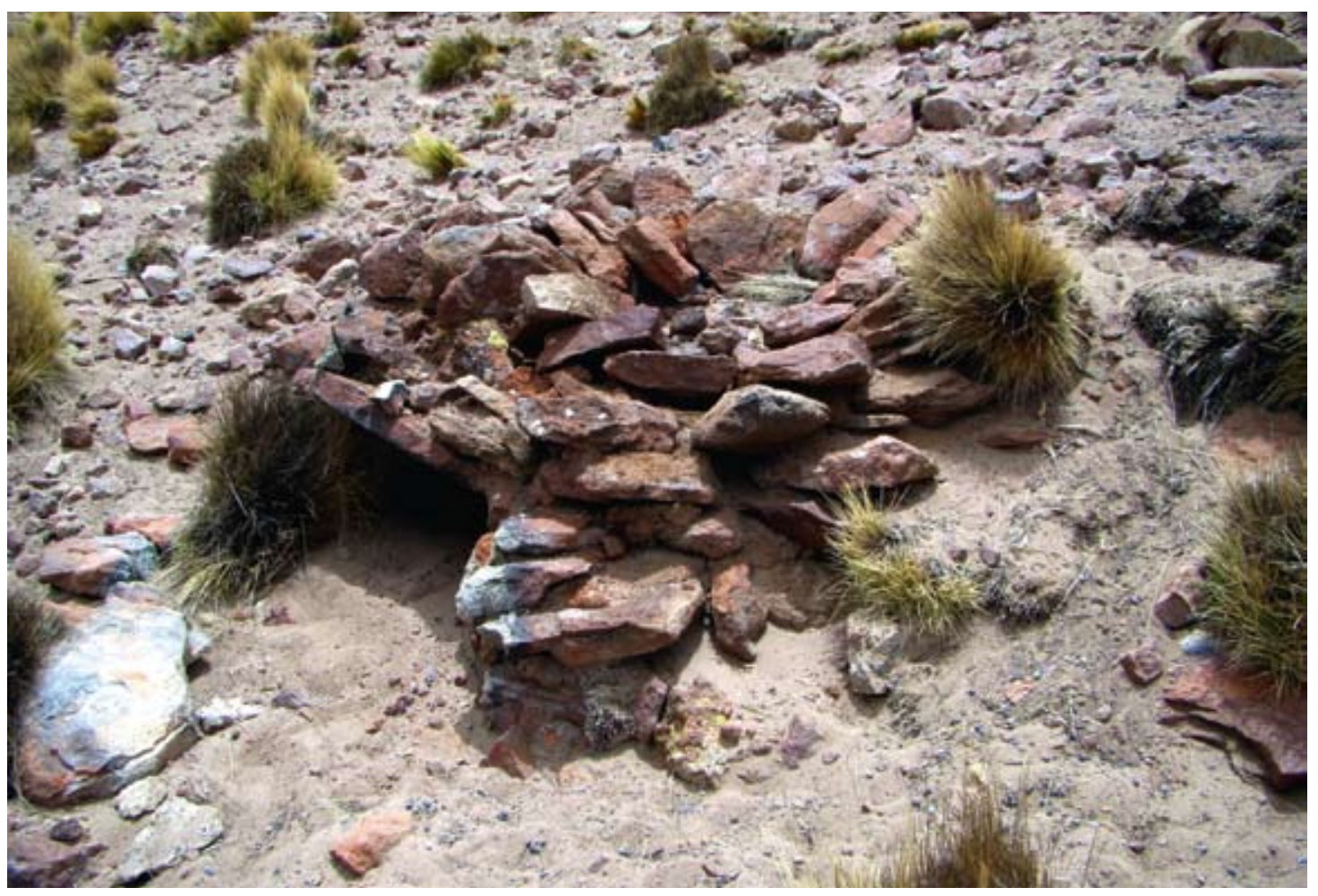

Figura 21. Casablanca. Horno de fundición.

Figure 21. Casablanca. Smelting furnace. 


\section{DISCUSIÓN}

\section{Época prehispánica}

Tanto las investigaciones previas como nuestros propios trabajos de campo han permitido el registro de grandes extensiones cubiertas por pozos y trincheras para la extracción de sedimentos auríferos en la Puna de Jujuy. Sin embargo, no podemos asegurar aún que éstos daten de época prehispánica. De todas maneras, es preciso señalar que tanto los inkas como los españoles explotaron probablemente los yacimientos ya conocidos por los indígenas locales, y que las labores mineras perturban los contextos anteriores y provocan la destrucción de los restos más antiguos. En este contexto, sospechamos que en los casos de Rinconada y Santa Catalina las labores mineras pudieron comenzar antes de la llegada de los españoles. En el caso de los pozos e instrumentos de molienda de Coyahuayma, que son indicadores de actividades mineras y de procesamiento de minerales, la cerámica inka hallada en el lugar nos permite suponer con más fundamento el inicio de la explotación del oro local en época prehispánica.

Los hornos hallados en Tabladitas 1 y río Candado 13, los únicos posiblemente prehispánicos de los que hemos registrado, parecen tratarse, por su diseño y tamaño, de estructuras destinadas más bien a una primera fundición de los minerales extraídos del yacimiento. El metal obtenido seguramente debía ser luego refundido y refinado en otro tipo de estructura de combustión. Es decir, estos hornos habrían sido un implemento vinculado más bien con el procesamiento de minerales, quizás para facilitar su transporte posterior reduciendo el volumen del material estéril, que con la fabricación de objetos metálicos. La notable escasez de evidencias de producción metalúrgica en los grandes asentamientos de la Puna y en las áreas estudiadas por nosotros, tales como moldes, crisoles, escoria, etc., permite formular que probablemente gran parte de los minerales extraídos de los yacimientos puneños eran trasladados a otras áreas. En realidad, si se observan las evidencias mencionadas, parece ser que los grupos puneños tuvieron una mayor orientación hacia las actividades mineras, en lugar de metalúrgicas.

Todo esto nos permite mantener nuestra propuesta de que probablemente sean los puneños los que han explotado los yacimientos de oro, estaño y plata localizados en el altiplano y los que se han encargado de la distribución de los minerales. No observamos hasta el momento la existencia de grupos de otras áreas dedicados a la extracción de minerales en la Puna. Trabajos arqueológicos y etnohistóricos han permitido documentar claramente la existencia en tiempos prehispánicos, coloniales y modernos de pastores-mineros en los Andes Centro Sur (Lozano Machuca 1992 [1581]; Berenguer 1994; Núñez 1994, 1999; entre otros). El mantenimiento de rebaños de llamas fue una actividad totalmente compatible con la explotación minera, combinación que perduró desde por lo menos el 1000 AC en el norte de Chile (Núñez 1994, 1999), hasta épocas coloniales y modernas en Lípez, sudoeste de Bolivia (Lozano Machuca 1992 [1581]; Nielsen 2000).

También ha sido ampliamente documentado que son los pastores los que normalmente conectan diversos ambientes para intercambiar lo que ellos producen por los elementos que necesitan, y que una caravana no se organiza para obtener y trasladar un solo producto. Por el contrario, una característica de los caravaneros es su capacidad para combinar diversas maneras de obtener distintos artículos en un mismo viaje (Núñez \& Dillehay 1995 [1979]; Núñez 1999; Nielsen 2000; entre otros).

Es probable que los pastores de los sectores económicamente menos favorables de la Puna jujeña hayan recurrido a la explotación y el tráfico de minerales requeridos por grupos de otras áreas (como Quebrada de Humahuaca y norte de Chile), para articularse de esa manera a una red de intercambio que les permitiera acceder a los artículos que ellos mismos necesitaban (Angiorama 2006). En cambio, para los pastores de áreas más ricas en recursos agropastoriles, como los del Sur de Pozuelos, la actividad minera parece haber sido secundaria. Esto es lo que nuestros estudios sugieren hasta el momento.

Para la época inka, se ha planteado repetidamente que fueron precisamente la riqueza en minerales metalíferos y la existencia de una larga tradición metalúrgica en algunos sectores del Noroeste Argentino, los motivos principales de la anexión de estos territorios al Imperio. En nuestras áreas de estudio el interés inka en los metales locales puede verse con claridad únicamente en Coyahuayma. A diferencia de lo que postularon otros investigadores, los trabajos intensivos que hemos realizado en Fundiciones, Santo Domingo y el Sur de Pozuelos no han dado como resultado el hallazgo de evidencias que nos permitan asegurar que la presencia inka en esas regiones -donde construyeron un importante ramal del camino principal andino, y tomaron y remodelaron asentamientos preexistentes- haya tenido alguna vinculación con intereses minero-metalúrgicos.

\section{Época colonial}

Tanto las investigaciones históricas, como los relatos de viajeros y geólogos destacan la importancia de los 
recursos minerales de la región durante época colonial. Las evidencias registradas mediante las prospecciones realizadas en las áreas de estudio permiten dar cuenta de esas prácticas minero-metalúrgicas llevadas a cabo durante la etapa colonial. Sin embargo, determinar la cronología exacta de estas evidencias resulta mucho más difícil.

En cuanto al oro, obtenido fundamentalmente de las arenas auríferas de los ríos, se sabe que fue un metal muy importante durante la Colonia y el período independiente, pero habría sido poco atractivo para explotaciones a gran escala. En esta actividad, participaban tanto españoles como indígenas (Palomeque 2000). En los tres sectores de estudio hay abundantes evidencias de lavado de oro, tanto en forma de trincheras y pozos como en estructuras para el manejo del agua. Las mismas se encuentran en general asociadas a refugios pequeños, donde el minero pernoctaba mientras duraba el período de actividad. Brackebusch (1966 [1893]: 229) da cuenta de la actividad solitaria del minero y describe su hogar diciendo que las casas no le brindan "abrigo contra las heladas, vientos y lluvia. Un montón de piedras crudas colocado en forma de anillo (la llamada pirca), sin techo, forma su hogar y dormitorio, monturas y un par de mantas viejas o harapos forman su lecho". Gil Montero (2004) atribuye esta descripción, sin embargo, más a la influencia del trabajo minero europeo que a las propias observaciones en la Puna, ya que los expedientes judiciales que esta autora trabajó mencionan actividades grupales donde participaban también las mujeres. Las descripciones que realiza Boman (1992 [1908]: 695) también involucran un trabajo familiar: "un hombre, dos mujeres y tres niños". Por el contrario, las evidencias registradas hasta el momento por nosotros en distintos parajes dan cuenta de actividades individuales o de grupos muy reducidos, sin gran inversión en infraestructura, a la manera que Brackebusch lo relata.

Aunque la reocupación sucesiva de los espacios nos impide ubicar las trincheras y lavaderos en un momento histórico en particular, las evidencias observadas confirman la importancia de estas tareas para los habitantes de la región.

En cuanto a las prácticas de fundición de minerales, las instalaciones registradas permiten ubicarlas en un período temporal más acotado, aunque sólo la combinación de la investigación arqueológica con la histórica, tarea que hemos iniciado, lograrán determinar los momentos precisos de funcionamiento de los emprendimientos e identificar a los agentes sociales que los llevaron a cabo.

A pesar de las particularidades de cada sitio, se pueden distinguir ciertas similitudes que permiten agruparlos según estas semejanzas. El horno registrado en la Quebrada de Chajarahuaico es un caso único debido a que su morfología difiere del resto al no presentar la estructura abovedada que los distingue. Además, no se cuenta con ninguna información bibliográfica u oral que permita contextualizar las actividades de fundición llevadas a cabo en el lugar. Sólo se sabe que la ocupación de una de las cercanas estructuras rectangulares se habría dado en época colonial, pero no hay evidencias que permitan asegurar que ambas estructuras hayan sido contemporáneas. La queñoa de más de 300 años, de crecimiento posterior al uso del horno es, por el momento, la única clave con la que contamos para estimar la antigüedad de esta estructura.

El segundo tipo de horno registrado es el que se encuentra en ambos complejos del Paraje de Fundiciones: Fundiciones 1 y 2. El diseño de los mismos se repite, aunque con diferencias en los detalles. Los hornos están compuestos por una bóveda con un orificio superior circular y cierto número de aberturas, conectada por un extremo a una caja prismática y por el otro a una chimenea cónica. Fundiciones 2 presenta una particularidad que no fue hallada en ninguno de los otros sitios: la existencia de hornos ubicados en un recinto preparado específicamente para albergarlos. Estudios futuros permitirán distinguir si éstos tenían una función diferente a la de los que se encuentran fuera del recinto.

El tercer tipo de horno, hallado en Pan de Azúcar 26 y Casablanca, es similar al anterior ya que presenta una bóveda con orificio circular superior y diversos orificios laterales. Sin embargo, además de la conexión a la chimenea (en todos los casos parcialmente conservada), presenta un segundo conducto, que llevaría a una cámara no visible desde el exterior y sellada, por lo menos en la actualidad. Por otra parte, es curioso que en ninguno de los hornos se haya conservado la caja de fuego, sino sólo posibles cimientos de las mismas, lo que hace pensar que tal vez ésta no estaba presente como en los hornos del segundo grupo o que pudiera ser diferente a la de éstos.

Más allá de las diferencias entre los dos últimos grupos, ambos presentan hornos denominados de tipo reverbero, que representan una tecnología de fundición diferente a la de las huayras prehispánicas o de los hornos castellanos en los que el mineral y el combustible se colocan en la misma cámara. En los hornos de tipo reverbero, el combustible se ubica en una caja de fuego conectada a la bóveda en la que se encuentra el mineral a fundir, es decir, que son los productos de la combustión (los gases calientes) los que toman contacto con la carga y no el combustible. ${ }^{3}$ 
La presencia de hornos de tipo reverbero en estos sitios indica que son emprendimientos de época colonial, ya que es una tecnología introducida por los españoles y no prehispánica. El hallazgo de este tipo de hornos en Pan de Azúcar no resulta sorprendente debido a la importancia que cobró este cerro en distintos momentos del período colonial (Palomeque 2000; Sica \& Ulloa 2007; entre otros). En el caso de Fundiciones, como se ha mencionado, es identificado como un yacimiento que para fines del siglo XIX se encontraba abandonado pero que había sido explotado en el pasado y debía serlo nuevamente en el futuro debido a su potencial riqueza (Hóskold 1889; Brackebusch 1981 [1883]; Tello 1988 [1888]). A partir de nuestras recientes investigaciones en Fundiciones 1 podemos postular que la fundición de minerales de plata y plomo posiblemente habría tenido lugar allí a fines del siglo XVIII (Becerra 2009). Del complejo Casablanca, por el contrario, no se cuenta hasta el momento con referencias escritas sobre su explotación.

Para ubicar cronólogicamente a los emprendimientos mineros descritos, al menos de modo tentativo, consideramos necesario tener en cuenta la historia de las explotaciones minero-metalúrgicas en la región, y considerar además la escala y características de cada complejo. En cuanto al primer punto, como se ha mencionado previamente, las explotaciones mineras en la Puna de Jujuy son promovidas por los españoles desde momentos tempranos. Sin embargo, el control y conocimiento de la región en estos primeros tiempos habría sido parcial y ligado a las riquezas de la zona (Gil Montero 2004). Es recién en la segunda mitad del siglo XVIII, cuando se conforman empresas mineras organizadas y con proyección a mediano plazo, como la compañía iniciada por Ángel Antonio de la Bárcena y Manuel Fernández de Baldivieso en 1789 para beneficiar a lo largo de diez años las minas de Pan de Azúcar, del cerro de San Pedro de Agua Caliente en la jurisdicción de Atacama, y todas aquellas minas de oro, plata, cobre y plomo que se descubrieren (Ulloa 2005; Becerra 2009).

Consideramos que son emprendimientos de este segundo tipo (compañías organizadas, con recursos y logística considerable) los que pueden llevar adelante complejos mineros de la escala registrada para Fundiciones 1 y 2, o Casablanca. Esto nos lleva a ubicar estas instalaciones en este lapso temporal. Pan de Azúcar 26, que está conformado por un solo horno y no tiene estructuras asociadas, resulta diferente a los otros tres complejos, que, aunque no a gran escala, requirieron de una inversión importante en recursos y personal. No podemos asociar el horno de Pan de Azúcar 26 con una compañía minera como la mencionada para este cerro en la segunda mitad del siglo XVIII Más bien parece haber sido un emprendimiento personal a baja escala. Éste pudo haber sido realizado tanto en los primeros momentos de explotación del yacimiento como a finales del período colonial.

\section{CONSIDERACIONES FINALES}

Somos conscientes de que este trabajo es apenas una primera aproximación al tema. Sólo una investigación más profunda de la documentación histórica regional y de las evidencias arqueometalúrgicas recuperadas permitirá avanzar en los planteos que hemos realizado y generar nueva información sobre la antigüedad y el funcionamiento de cada una de las instalaciones descritas en este artículo, y sobre los procesos minero-metalúrgicos desarrollados en la Puna de Jujuy. Es en este sentido en el que continuaremos trabajando.

RECONOCIMIENTOS Esta investigación ha sido posible gracias a subsidios otorgados por CONICET y FONCYT. Agradecemos muy especialmente a cada uno de los amigos que han participado en los trabajos de campo realizados, y a Marcelo Prieto ("Peralta"), que nos acompañó cada vez que estuvimos en Fundiciones y respondió con paciencia cada una de nuestras preguntas. Ninguno de ellos, sin embargo, es responsable de lo expresado en este artículo.

\section{NOTAS}

${ }^{1}$ A pesar de la relevancia de la información brindada por estos informes y relatos, la asignación temporal y específicamente la adjudicación de las evidencias de los trabajos minero-metalúrgicos registrados a ciertos grupos, como los "jesuitas", debe ser revisada con mucha atención. Hasta el momento no hay evidencias de que esta Orden se haya establecido en este particular sector de la Puna de Jujuy y, sin embargo, según casi todos los informes publicados habría sido la responsable de la mayoría de las explotaciones.

${ }^{2}$ Hasta el momento hemos excavado 14 recintos completos, y sondeado ocho recintos más, un alero, dos cuevas y tres refugios construidos bajo aleros o al pie de grandes paredones (Angiorama 2009a).

${ }^{3}$ Para una descripción detallada ver el Arte de los metales de Alonso Barba (1939 [1640]).

\section{REFERENCIAS}

AlBeck, M., 2001. La Puna Argentina en los períodos Medio y Tardío. En Historia argentina prebispánica, E. Berberián \& A. Nielsen, Eds., Tomo I, pp. 347-388. Córdoba: Editorial Brujas.

Alfaro De Lanzone, L. C., 1988. Excavación de la cuenca del río Doncellas. Reconstrucción de una cultura olvidada en la Puna jujeña. San Salvador de Jujuy: Edit. Imprenta del Estado de la Provincia de Jujuy.

Alonso Barba, A., 1939 [1640]. Arte de los metales. Biblioteca boliviana $\mathrm{N}^{\circ}$ 8. La Paz: Imp. Artística. 
Angiorama, C., 2003. Producción y circulación de objetos de metal en la Quebrada de Humahuaca en momentos prehispánicos tardíos (900-1535 d.C.). Tesis Doctoral Inédita, Facultad de Ciencias Naturales e Instituto Miguel Lillo, Universidad Nacional de Tucumán, San Miguel de Tucumán.

— 2006. ¿Mineros quebradeños o altiplánicos? La circulación de metales y minerales en el extremo noroccidental de Argentina (1280-1535 AD). Intersecciones en Antropología 7: 147-161, Olavarría.

— 2009a. La presencia del IAM en la Puna jujeña: el proyecto arqueológico Sur de Pozuelos. En Rastros en el camino. Trayectos e identidades de una institución, C. Aschero, P. Arenas \& C. Taboada, Eds. San Miguel de Tucumán: Editorial de la Universidad Nacional de Tucumán (en prensa).

— 2009b. La ocupación del espacio en el sur de Pozuelos (Jujuy) durante época prehispánica tardía y colonial.

Becerra, M. F., 2009. Prácticas minero-metalúrgicas durante el período colonial: el complejo Fundiciones 1 como caso de estudio (Fundiciones, Departamento de Rinconada, Jujuy, Argentina). Tesina de Grado inédita, Facultad de Ciencias Naturales e Instituto M. Lillo, Universidad Nacional de Tucumán, San Miguel de Tucumán.

Becerra, M. F.; C. Angiorama \& N. Nieva, 2010. Estudios arqueométricos de evidencias de producción minero-metalúrgica durante época colonial en Fundiciones 1 (Departamento Rinconada, Jujuy, Argentina). Intersecciones en Antropología, Olavarría (en prensa).

Berenguer, J., 1994. Asentamientos, caravaneros y tráfico de larga distancia en el norte de Chile: el caso de Santa Bárbara. En De costa a selva. Producción e intercambio entre los pueblos agroalfareros de los Andes Centro Sur, M. Albeck, Ed., pp. 17-46. Tilcara: Instituto Interdisciplinario Tilcara, Facultad de Filosofía y Letras, Universidad de Buenos Aires.

Boman, E., 1992 [1908]. Antigüedades de la Región Andina de la República Argentina y del desierto de Atacama, Vols. I y II. San Salvador de Jujuy: Universidad Nacional de Jujuy.

Brackebusch, L., 1981 [1883]. Por los caminos del Norte. Tucumán Colegio de Graduados en Ciencias Geológicas de Tucumán.

1966 [1893]. Las condiciones de la minería en la República Argentina. Boletín de la Academia Nacional de Ciencias, Tomo XLV.

Casanova, E., 1938. Investigaciones arqueológicas en Sorcuyo, Puna de Jujuy. Anales del Museo Argentino de Ciencias Naturales 80, Tomo xxxIx, Buenos Aires.

Catalano, E., 2004. Antecedentes y estructura histórica de la minería argentina. En Historia de la minería argentina, Tomo I, E. Lavandaio \& E. Catalano, Eds., Capítulo 1., pp. 1-176. Buenos Aires: SEGEMAR

DEBENEDETTI, S., 1910. Exploración arqueológica de los cementerios prehistóricos de la Isla de Tilcara (Quebrada de Humahuaca, Provincia de Jujuy). Publicaciones de la Sección Antropológica $\mathrm{N}^{\circ}$ 6. Buenos Aires: Facultad de Filosofía y Letras, Universidad de Buenos Aires.

— 1930. Chulpas en las cavernas del río San Juan Mayo. Notas del Museo Etnográfico No 1: 5-50. Buenos Aires: Universidad de Buenos Aires.

Gil Montero, R., 2004. Caravaneros y trashumantes en los Andes Meridionales. Población y familia indígena en la Puna de Jujuy 1770-1870. Perú: Instituto de Estudios Peruanos.

— 2007. La Puna: población, recursos y estrategias. En Jujuy en la bistoria. De la Colonia al siglo xx, A. Teruel \& M. Lagos, Dir., pp. 373-401. Jujuy: Unidad de Investigación en Historia Regional, Facultad de Humanidades y Ciencias Sociales, Editorial de la Universidad Nacional de Jujuy.

González, A. R., 1980. Patrones de asentamiento incaico en una provincia marginal del imperio. Implicaciones socioculturales. Relaciones de la Sociedad Argentina de Antropología, NS, XIV, I: 63-82, Buenos Aires.
- 1992. Las placas metálicas de los Andes del Sur. Contribución al estudio de las religiones precolombinas. Materialien zur Allgemeinen und Vergleichenden Archäologie 46. München: K.A.V.A.

GonzÁlez, L., 2004. Bronces sin nombre. La metalurgia prebispánica en el Noroeste Argentino, Buenos Aires: Ediciones Fundación Ceppa.

HósKold, H., 1889. Memoria general y especial sobre las minas, metalurgia, leyes de minas, recursos de ventajas, etc. de la explotación de minas en la República Argentina. Buenos Aires: Courrier de La Plata.

Krapovickas, P., 1987-1988. Nuevos fechados radiocarbónicos para el sector oriental de la Puna y la Quebrada de Humahuaca. Runa XVII-XVIII: 207-219, Buenos Aires.

Krapovickas, P. \& S. AleKsandrowicz, 1986-1987. Breve visión de la cultura de Yavi. Anales de Arqueología y Etnología 41-42: 83-127, Mendoza.

Krapovickas, P. \& E. Cigliano, 1962-1963. Investigaciones arqueológicas en el valle del río Grande de San Juan (Puna Argentina). Anales de Arqueología y Etnología xviI-XviII: 71-118, Mendoza.

Lehman-Nistche, R., 1902. Catálogo de las antigüedades de la Provincia de Jujuy. Revista del Museo de La Plata, Vol. XI, La Plata.

Lozano Machuca, J., 1992 [1581]. Carta del Factor de Potosí Lozano Machuca (al Virrey del Perú Don Martín Enríquez) en que Da Cuenta de Cosas de Aquella Villa y de las Minas de los Lipes. Estudios Atacameños 10: 30-34.

Mena, F., 1916 [1772]. Fundación de Salta. Descripción y Narración Historial de la Antigua Provincia del Tucumán. En La Patria Vieja. Cuadros históricos. Guerra. Política. Diplomacia, G. Rodríguez, Comp., pp. 289-462. Buenos Aires: Compañía SudAmericana de Billetes de Banco.

Méndez, V., 1999. Historia del desarrollo minero argentino. En Recursos minerales de la República Argentina, Anales 35. Buenos Aires: SEGEMAR.

Nielsen, A., 2000. Andean Caravans: An Ethnoarchaeology, Tesis Doctoral, University of Arizona, Tucson, University Microfilms, Ann Arbor.

NúÑEZ, L., 1994. Emergencia de complejidad y arquitectura jerarquizada en la Puna de Atacama: las evidencias del sitio TULAN-54. En De costa a selva. Producción e intercambio entre los pueblos agroalfareros de los Andes Centro Sur, M. Albeck, Ed., pp. 85-108, Tilcara: Instituto Interdisciplinario Tilcara, Facultad de Filosofía y Letras, Universidad de Buenos Aires.

— 1999. Valoración minero-metalúrgica circumpuneña: Menas y mineros para el Inka rey. Estudios Atacameños 18: 177-221.

NuÑEz, L. \& T. Dillehay, 1995 [1979]. Movilidad giratoria, armonía social y desarrollo en los Andes Meridionales: Patrones de tráfico e interacción económica. Antofagasta: Universidad Católica del Norte.

Olivera, D., 1991. La ocupación Inka en la Puna Meridional argentina: Depto. Antofagasta de la Sierra, Catamarca. Comechingonia, El imperio Inka. Actualización y perspectivas por registros arqueológicos y etnográficos, Número Especial II: 33-72, Córdoba.

PAlomeque, S., 1994. Intercambios mercantiles y participación indígena en la "Puna de Jujuy" a fines del Período Colonial. Andes 6: 13-49, Salta.

- 2000. Acceso a los recursos y participación mercantil en una zona rural surandina (Puna de Jujuy, siglos XVIII y XIX). En Mercados indígenas en México y los Andes, siglos XVIII y XIX, J. Silva \& A. Escobar, Coord., pp. 177-210. México D. F.: Instituto Mora y CIESAS.

— 2006. La 'Historia' de los señores étnicos de Casabindo y Cochinoca (1540-1662). Andes 17: 139-194, Salta.

Pérez, S., 2006-2007. Los metales de la "Colección Doncellas" y el proceso de producción metalúrgico. Cuadernos del Instituto Nacional de Antropología y Pensamiento Latinoamericano 21: 191-202, Buenos Aires. 
RAFFINO, R., 1978. La ocupación Inka en el N. O. Argentino: actualización y perspectivas. Relaciones de la Sociedad Argentina de Antropología xII: 95-121, Buenos Aires.

- 1981. Los Inkas del Kollasuyu. Buenos Aires: Ramos Americana.

Raffino, R.; R. Alvis, L. BAldini, D. Olivera \& M. RAviñA, 1985.

Hualfin-Watungasta-Watungasta. Tres casos de urbanización Inka en el N. O. argentino. Cuadernos del Instituto Nacional de Antropología 10: 425-455, Buenos Aires.

Rodríguez OrRego, L., 1986. La metalurgia precolombina de los Andes Meridionales. Una síntesis regional. En Metalurgia de América Precolombina, pp. 381-402. Bogotá: Banco de la República $45^{\circ}$ Congreso Internacional de Americanistas.

SAlas, M., 1945. El antigal de Ciénaga Grande (Quebrada de Purmamarca, Provincia de Jujuy). En Publicaciones del Museo Etnográfico, Serie A, V., pp. 1-268. Facultad de Filosofía y Letras, Universidad de Buenos Aires. Buenos Aires.

Schuel, K., 1930. Ruinas de las poblaciones de los indígenas de la Provincia de Jujuy. En Quinta Reunión de la Sociedad de Patología Regional del Norte Argentino, Vol. 2, pp. 1430-1450, Buenos Aires.

SGrosso, P., 1943. Contribución al conocimiento de la minería y geología del NOA. Boletín $\mathrm{N}^{\circ} 53$, Buenos Aires: Ministerio de Agricultura de la Nación.
Sica, G. \& M. UlloA, 2007. Jujuy en la Colonia. De la Fundación de la ciudad a la crisis del orden colonial. En Jujuy en la bistoria. De la Colonia al siglo xx, A. Teruel \& M. Lagos, Dir., pp. 41-84. Jujuy: Unidad de Investigación en Historia Regional, Facultad de Humanidades y Ciencias Sociales, Editorial de la Universidad Nacional de Jujuy.

Tello, D. E., 1988 [1888]. Descripción de la Provincia de Jujuy. Informes, objetos y datos que presenta el Comisionado Provincial, Senador Nacional D. Eujenio Tello a la Exposición Universal de 1889 en París. San Salvador de Jujuy: Universidad Nacional de Jujuy.

UlLOA, M., 2005. Comerciantes, pulperos, hacendados y buscadores de oro. Españoles en la Puna de Jujuy a fines del siglo xviII. En CD Actas del VI Congreso Internacional de Etnobistoria, Buenos Aires.

Ventura, B., 1985 Ms. Metalurgia: un aspecto poco conocido en la arqueología de las Selvas Occidentales. Informes de Investigación 2, pp. 5-82. Buenos Aires: Programa de Estudios Prehistóricos. CONICET-Universidad de Buenos Aires.

Zappettini, E., 2004. Oro en la Provincia de Jujuy. En Historia de la Minería Argentina, Tomo II, E. Lavandaio \& E. Catalano, Eds., pp. 69-75. Buenos Aires: SEGEMAR. 